\title{
FORMOSAT-3/COSMIC Constellation Spacecraft System Performance: After One Year in Orbit
}

\author{
Chen-Joe Fong, Member, IEEE, Shan-Kuo Yang, Chung-Huei Chu, Cheng-Yung Huang, Jia-Jing Yeh, \\ Chen-Tsung Lin, Tien-Chuan Kuo, Tie-Yue Liu, Nick L. Yen, Shao-Shing Chen, Ying-Hwa Kuo, \\ Yuei-An Liou, Senior Member, IEEE, and Sien Chi
}

\begin{abstract}
The FORMOSAT-3 mission, also known as Constellation Observing System for Meteorology, Ionosphere, and Climate (COSMIC), is the third major project of the Formosa Satellite (FORMOSAT) series implemented by the National Space Organization of Taiwan. FORMOSAT-3/COSMIC is a joint Taiwan/U.S. mission consisting of six identical low Earth orbit satellites. All six cluster satellites were successfully launched by a single Minotaur launch vehicle on April 15, 2006. The retrieved global positioning system (GPS) radio occultation (RO) data have been freely available online to the science community since shortly after the completion of satellite bus in-orbit checkout. Having completed the verification and validation, the worldwide science communities are highly satisfied with the RO data. Scientists have hailed the RO sensors as offering the most accurate, precise, and stable thermometers in space. After one year in orbit, all six FORMOSAT-3/COSMIC satellites were in good condition (except FM2, which had power shortage issues) and were on their way toward the final constellation of six separate orbit planes with $30^{\circ}$ separation. Four out of six satellites had already reached their final mission orbit of $800 \mathrm{~km}$ by mid-May 2007. Together, the six satellites have generated a total of more than $2500 \mathrm{RO}$ data per day. However, only $50 \%-70 \%$ of the RO data as received one year after launch could be retrieved into useful atmosphere profiles. The retrieved RO data, about 1800 per day on average, have been assimilated into numerical weather prediction models by many major weather forecast centers and research institutes. This paper provides an overview of the constellation mission, the spacecraft system performance after one year in orbit, the technical challenges we have encountered, and the performance enhancements we have accomplished.
\end{abstract}

Manuscript received September 1, 2007; revised May 4, 2008. Current version published October 30, 2008.

C.-J. Fong is with the National Space Organization, Hsinchu 300, Taiwan, and also with the Department of Photonics and Institute of Electro-Optical Engineering, National Chiao Tung University, Hsinchu 300, Taiwan (e-mail: cjfong@nspo.org.tw).

S.-K. Yang, C.-H. Chu, J.-J. Yeh, C.-T. Lin, T.-C. Kuo, T.-Y. Liu, N. L. Yen, and S.-S. Chen are with the National Space Organization, Hsinchu 300, Taiwan (e-mail: albert@nspo.org.tw).

C.-Y. Huang was with the Science Development Division, National Space Organization, Hsinchu 300, Taiwan. He is now with the Institute for Scientific Research, Boston College, Chestnut Hill, MA 02135 USA (e-mail: huangcn@bc.edu).

Y.-H. Kuo is with the University Corporation for Atmospheric Research, Boulder, CO 80307 USA (e-mail: kuo@ucar.edu).

Y.-A. Liou is with the Center for Space and Remote Sensing Research, National Central University, Chungli 320, Taiwan (e-mail: yueian@csrsr. ncu.edu.tw).

S. Chi is with the Department of Photonics and Institute of Electro-Optical Engineering, National Chiao Tung University, Hsinchu 300, Taiwan, and also with the Department of Electrical Engineering, Yuan Ze University, Chungli 320, Taiwan (e-mail: schi@mail.nctu.edu.tw).

Color versions of one or more of the figures in this paper are available online at http://ieeexplore.iee.org.

Digital Object Identifier 10.1109/TGRS.2008.2005203
Index Terms-Constellation, Constellation Observing System for Meteorology, Ionosphere, and Climate (COSMIC), FORMOSAT-3, radio occultation ( $\mathrm{RO})$, remote sensing, satellite, system performance.

\section{INTRODUCTION}

$\mathbf{F}$ ORMOSAT-3/CONSTELLATION Observing System for Meteorology, Ionosphere, and Climate (COSMIC) is a joint mission of Taiwan and the U.S. The mission consists of six identical low Earth orbit satellites and is being carried out by Taiwan's National Space Organization (NSPO) and the U.S. University Corporation for Atmospheric Research (UCAR), Orbital Sciences Corporation (OSC), National Aeronautics and Space Administration's Jet Propulsion Laboratory (JPL), and Naval Research Laboratory (NRL). This is the third major project of the Formosa Satellite (FORMOSAT) series implemented by the NSPO. FORMOSAT-3/COSMIC's mission is to collect a large amount of atmospheric data for meteorological, climatic, ionospheric, and geodetic research, as well as for weather forecasting and space weather monitoring [1]-[5]. All six satellites were successfully launched by a single Minotaur launch vehicle from Vandenberg Air Force Base (VAFB) in California at 1:40 UTC (Coordinated Universal Time) on April 15, 2006 into the same orbit plane of a designated circular parking orbit, at an altitude of $516 \mathrm{~km} \mathrm{[6],} \mathrm{[7].}$

The global positioning system (GPS) radio occultation (RO) science data have been freely available online to the science community since shortly after the completion of satellite inorbit checkout [8], [9]. Preliminary results show that this new constellation GPS RO system can boost the accuracy of the prediction of hurricane behavior, significantly improve longrange weather forecasts, and monitor climate change with unprecedented accuracy and precision. The worldwide science community is highly satisfied with the science data results. Scientists have described the RO sensors as the most accurate, precise, and stable thermometer in space for measuring global and regional climate change [10], [11].

Preliminary assessments have also shown that the GPS RO data from FORMOSAT-3/COSMIC are of better quality than those from the previous missions [7], [12]-[15], e.g., the proofof-concept GPS/Meteorology experiment, the Challenging Mini-Satellite Payload (CHAMP), and the Satelite de Aplicaciones Cientificas-C missions. The GPS RO soundings penetrate much farther down into the troposphere; from $70 \%$ to $90 \%$ of the soundings reach to within $1 \mathrm{~km}$ of the surface on a global basis [16]-[19]. As a result, the FORMOSAT-3/COSMIC 
TABLE I

FORMOSAT-3/COSMIC MISSION CHARACTERISTICS

\begin{tabular}{|l|l|}
\hline Number & Six identical satellites \\
\hline Weight & $\sim 61 \mathrm{~kg}$ (with payload and fuel) \\
\hline Shape & Disc-shape of $116 \mathrm{~cm}$ diameter, $18 \mathrm{~cm}$ in height \\
\hline Orbit & $800 \mathrm{~km}$ altitude, circular \\
\hline Inclination Angle & 72 degrees \\
\hline Argument of latitude & 52.5 degrees apart \\
\hline Power & $\sim 81$ W orbit average \\
\hline Communication & S-band uplink (32 kbps) and downlink (2 Mbps) \\
\hline Sounding & $\sim 2000$ soundings per day \\
\hline Data Latency & 15 minutes to 3 hours \\
\hline Design and Mission life & 5 years \\
\hline Launch date & 15 April 2006 \\
\hline
\end{tabular}

GPS RO data are making a positive impact on operational global weather forecast models. The European Centre for Medium-range Weather Forecasts (ECMWF) began to use the FORMOSAT-3/COSMIC data operationally from December 12, 2006 [20]. The National Centers for Environmental Prediction (NCEP) announced that the GPS RO data from the FORMOSAT-3/COSMIC mission would go into operational use with the implementation of the system of Gridpoint Statistical Interpolation/Global Forecast System at NCEP on May 1, 2007 [21]. Several other global operational centers, e.g., Taiwan's Central Weather Bureau (CWB), the Canadian Meteorological Centre, the United Kingdom Meteorological Office (UKMO), and Météo France, plan to use FORMOSAT-3/ COSMIC data operationally later in 2007 [22], [23]. Hence, the FORMOSAT-3/COSMIC mission has become the world's first operational GPS RO constellation mission [22], [23]. This paper provides a constellation mission overview and reviews the spacecraft system performance after one year in orbit. It also assesses the technical challenges encountered and the performance enhancement achieved [24]-[26].

\section{Constellation Mission Overview}

The FORMOSAT-3/COSMIC mission requirements were defined by NSPO and UCAR in order to meet the needs of the atmospheric science communities. NSPO served as the prime contractor for the development, deployment, and operations of the FORMOSAT-3/COSMIC spacecraft, while OSC provided the spacecraft, integrated and tested the first Flight Model (FM), and delivered the ready kits to NSPO for five additional spacecraft. NSPO integrated and tested FMs 2-6 in the Satellite Integration and Test facility in Hsinchu, Taiwan, and then coordinated the effort to integrate the six spacecraft in a stack configuration with the Minotaur launch vehicle provided by the U.S. Air Force at VAFB in California. UCAR provided the payload suite of scientific instruments and the science data processing of scientific instruments. Each spacecraft is equipped with a GPS Occultation Experimental Receiver (GOX) payload, developed by JPL and built by Broad Reach Engineering, a Tiny Ionospheric Photometer (TIP) built by NRL, and a Tri-Band Beacon (TBB), also provided by NRL. Table I shows the FORMOSAT-3/COSMIC mission characteristics, and Fig. 1 shows the spacecraft in deployed configuration, along with its major components [13]-[15].

After the successful launch of FORMOSAT-3/COSMIC satellites, NSPO conducted mission operations from the
Satellite Operations Control Center (SOCC) with support from OSC, UCAR, and JPL for resolution of spacecraft anomalies, mission enhancement and scientific payload operations, and updating GOX payload firmware, respectively. The mission operation team in Taiwan is executing and managing all dayto-day activities of the system. Today, this team carefully conducts the deployment of the constellation and the constellation operations schedule in order to ensure that measurements are globally homogeneous and to minimize the latency of data fed into weather prediction models [13]-[15], [24], [25].

All science data are processed by the UCAR COSMIC Data Analysis and Archive Center (CDAAC) located in Boulder, CO, and then transferred to the Taiwan Analysis Center for COSMIC at the CWB, as well as to other facilities for science and data archival [8], [9]. The processed results are then passed from the CDAAC to the U.S.'s National Environmental Satellite, Data, and Information Service at National Oceanic and Atmospheric Administration (NOAA). These data are further routed to weather centers all over the world, including the Joint Center for Satellite Data Assimilation, NCEP, ECMWF, CWB, UKMO, the Japan Meteorological Agency, the Air Force Weather Agency, and others. The data under the operations team's integral teamwork effort are currently provided to these weather centers within $90 \mathrm{~min}$ (data latency requirement is $180 \mathrm{~min}$ ) of satellite on-orbit science data collection in order to be used by the operational weather forecast model [24], [25].

\section{Constellation Spacecraft System Performance: After One Year In Orbit}

\section{A. Constellation Spacecraft Performance Summary}

The FORMOSAT-3/COSMIC constellation provides a unique opportunity to assess the performance of multiple spacecraft at the same time. During the early weeks of the deployment, the satellites were spaced very closely together and in cluster formation. This has offered scientists a unique opportunity to verify the high precision of GPS RO measurements. Table II shows the constellation spacecraft performance summary as of April 15, 2007. After one year in orbit, all six FORMOSAT-3/COSMIC spacecraft were in good condition (except for the FM2 satellite, which had power shortage issues since March 2007) and were on their way toward the final constellation of six separate orbit planes with $30^{\circ}$ separation [6], [7], [13]-[15].

\section{B. Spacecraft Subsystem On-Orbit Performance Summary}

Table III shows the operational status of each subsystem in all six spacecraft. Table IV shows the spacecraft subsystem performance and its major functions. All the radio frequency (RF) uplink and downlink trend data show that the spacecraft meet the specified RF subsystem requirements. Suspected space weather disturbances, which are correlated to the spacecraft onboard computer reboot and spacecraft reset events, had no performance impact on the command and data handling subsystem and spacecraft system. The flight software subsystem (FSW) status of all six satellites is normal, and the spacecraft are recovered automatically as expected by design 


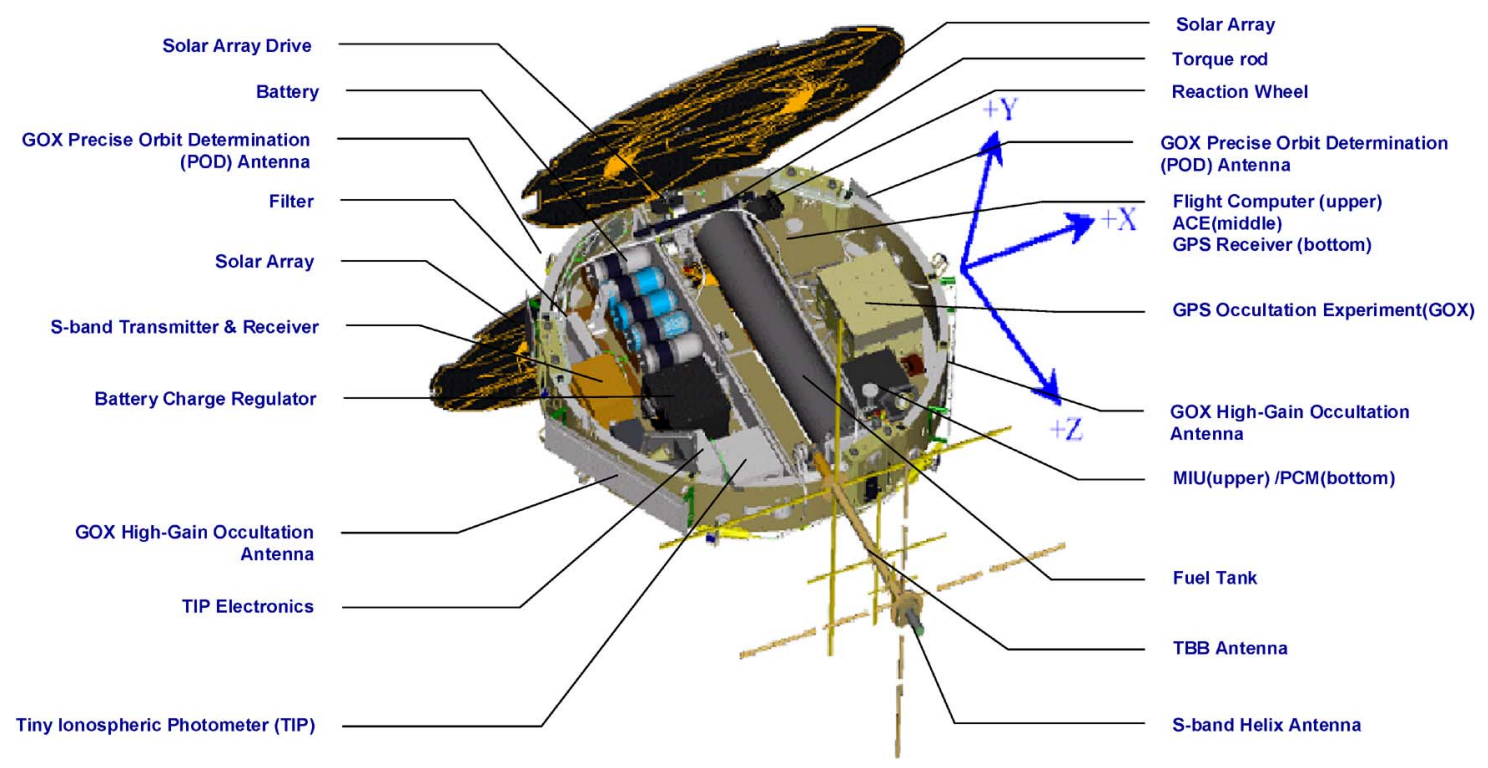

Fig. 1. FORMOSAT-3/COSMIC spacecraft in deployed configuration.

TABLE II

CONSTellation Spacecraft Performance Summary (APRIL 15, 2007)

\begin{tabular}{|c|c|c|}
\hline SC ID & & Summary \\
\hline FM1 & $\begin{array}{l}\square \\
\square \\
\square\end{array}$ & $\begin{array}{l}\text { Healthy } \\
\text { Bus GPSR GPS Non-Fixed -> Operation Solution } \\
\text { GOX Reboot Loop -> Auto Recovery }\end{array}$ \\
\hline FM2 & $\begin{array}{l}\square \\
\square \\
\square\end{array}$ & $\begin{array}{l}\text { Solar Array Power Shortage -> Reduced GOX Operation } \\
\text { BCR dMdC Charge Algorithm Issue-> CSD Charge or FSW update } \\
\text { Payload PCM DC Off -> TBB \& TIP Off }\end{array}$ \\
\hline FM3 & $\begin{array}{l}\square \\
\square \\
\square\end{array}$ & $\begin{array}{l}\text { Healthy } \\
\text { Bus GPSR GPS Non-Fixed -> Operation Solution } \\
\text { OCC2 (ANT03) SNR Decreasing -> Recovery after High Beta Angle }\end{array}$ \\
\hline FM4 & $\begin{array}{l}\square \\
\square\end{array}$ & $\begin{array}{l}\text { Healthy } \\
\text { Bus GPSR GPS Non-Fixed -> Operation Solution }\end{array}$ \\
\hline FM5 & $\square$ & Healthy \\
\hline FM6 & & $\begin{array}{l}\text { Healthy } \\
\text { Bus GPSR GPS Non-Fixed -> Operation Solution } \\
\text { GOX Reboot Loop -> Under Investigation }\end{array}$ \\
\hline
\end{tabular}

TABLE III

SpaceCraft Operation Status of Each Subsystem in All Six SPaCECraft (April 15, 2007)

\begin{tabular}{|c|c|c|c|c|c|c|c|c|}
\hline Spacecraft & $\begin{array}{c}\text { Operational } \\
\text { Mode }\end{array}$ & SC State & ACS Mode & EPS Mode & $\begin{array}{c}\text { C\&DH } \\
\text { Mode }\end{array}$ & GOX & TIP & TBB \\
\hline FM1 & Normal & Normal & Fixed-Yaw & Normal & High Rate & Operating & Operating & Plan VI \\
\hline FM2 & Normal & $\begin{array}{c}\text { Normal (Power } \\
\text { Shortage) }\end{array}$ & Fixed-Yaw & Normal & High Rate & $\begin{array}{c}\text { Reduced } \\
\text { Operating }\end{array}$ & Off & Off \\
\hline FM3 & Normal & Normal & Fixed-Yaw & Normal & High Rate & Operating & Operating & Plan VI \\
\hline FM4 & Normal & Normal & Fixed-Yaw & Normal & High Rate & Operating & Operating & Plan VI \\
\hline FM5 & Normal & Normal & Fixed-Yaw & Normal & High Rate & Operating & Operating & Plan VI \\
\hline FM6 & Normal & Normal & Fixed-Yaw & Normal & High Rate & Operating & Operating & Plan VI \\
\hline
\end{tabular}


TABLE IV

SPACECRAFT Subsystem PeRformance (APRIL 15, 2007)

\begin{tabular}{|c|c|c|}
\hline Unit & Major Function & One-Year Performance \\
\hline Payload (PL) & $\begin{array}{l}\text { GPS radio occultation } \\
\text { (RO) primary mission }\end{array}$ & $\begin{array}{l}\square \text { Trends on SNR data after FB4.3 uploaded did not show any } \\
\text { sign of degradation at all from the available data. } \\
\square \text { FM1 and FM6 had reboot loop issues and are still under } \\
\text { investigation. } \\
\square \text { TBB \& TIP are functioning OK. }\end{array}$ \\
\hline $\begin{array}{l}\text { Radio Frequency } \\
\text { Subsystem (RFS) }\end{array}$ & $\begin{array}{l}\text { RF uplink and } \\
\text { downlink }\end{array}$ & $\begin{array}{l}\text { № RF degradation observed from FM1 to FM6. } \\
\square \text { All RF trending data meet specified criteria. }\end{array}$ \\
\hline $\begin{array}{l}\text { Command and } \\
\text { Data Handling } \\
\text { Subsystem } \\
\text { (C\&DH) }\end{array}$ & $\begin{array}{l}\text { Command handling and } \\
\text { telemetry gathering, } \\
\text { health and } \\
\text { maintenance, GPS } \\
\text { receiver management }\end{array}$ & $\begin{array}{l}\text { The GPS Non-fixed on FM1, FM3, FM4 \& FM6 Bus GPS } \\
\text { receivers impacted onboard time maintenance, ACS } \\
\text { performance and TIP payload time stamping. Operation } \\
\text { Solution by upload State vector using GOX PVT data was } \\
\text { performed to eliminate all impacts. } \\
\square \text { The suspected space weather correlated onboard computer } \\
\text { reboot and spacecraft reset events have no performance } \\
\text { impact on C\&DH and Spacecraft }\end{array}$ \\
\hline $\begin{array}{l}\text { Flight Software } \\
\text { Subsystem (FSW) }\end{array}$ & $\begin{array}{l}\text { FC/ACS/BCR Flight } \\
\text { software, software } \\
\text { upload, payload, launch } \\
\text { vehicle interface }\end{array}$ & $\begin{array}{l}\square \text { FSW status on all satellites is normal; SC are automatically } \\
\text { recovered from abnormal conditions. } \\
\square \text { Under normal FSW condition, the error count increased rate } \\
\text { is smaller than 10/day. }\end{array}$ \\
\hline $\begin{array}{l}\text { Attitude Control } \\
\text { Subsystem (ACS) }\end{array}$ & $\begin{array}{l}\text { Control of nadir } \\
\text { pointing and sun } \\
\text { pointing, GPS data } \\
\text { processing }\end{array}$ & $\begin{array}{l}\square \text { Correct ACS mode transition was observed. } \\
\square \text { All six spacecraft performed their ACS functions on orbit as } \\
\text { expected. }\end{array}$ \\
\hline $\begin{array}{l}\text { Reaction Control } \\
\text { Subsystem (RCS) }\end{array}$ & $\begin{array}{l}\text { Orbital transfer and } \\
\text { raising }\end{array}$ & $\begin{array}{l}\text { FM2, FM5, FM6 and FM4 have arrived at the mission orbits, } \\
\text { and the remaining propellant masses for these three satellites } \\
\text { are around } 2.0 \mathrm{~kg}(\sim 30 \% \text { of full capacity) } \\
\text { RCS functions are all healthy and ready for any planned orbit } \\
\text { maneuvers in the future. }\end{array}$ \\
\hline $\begin{array}{l}\text { Thermal Control } \\
\text { Subsystem (TCS) }\end{array}$ & $\begin{array}{l}\text { Maintain avionics and } \\
\text { battery at operating } \\
\text { temperatures }\end{array}$ & $\begin{array}{l}\text { Thermal behavior of all six satellites is normal and in good } \\
\text { shape. }\end{array}$ \\
\hline $\begin{array}{l}\text { Electrical Power } \\
\text { Subsystem (EPS) }\end{array}$ & $\begin{array}{l}\text { Solar array and battery } \\
\text { charge control, power } \\
\text { switching, deployment } \\
\text { sequence }\end{array}$ & $\begin{array}{l}\square \text { No sensible degradation on all six satellite except FM2. } \\
\square \text { Solar power reduced on FM2 and Reduced GOX operation } \\
\text { plan was modified. } \\
\square \text { Pressure difference on FM1 FM4 reduced to safe range } \\
\text { (<650 psi) and stable now. } \\
\square \text { Power margin is estimated at } 40 \% \text { on solar power except } \\
\text { FM2. }\end{array}$ \\
\hline
\end{tabular}

from abnormal reboot/reset conditions. Under normal FSW conditions, the error count is less than ten per day. The thermal control subsystem is behaving nominally across the range of solar beta angles. There was an issue concerning excessive Earth horizon sensor (EHS) temperature increases at high beta angles, which has been resolved by an operations solution of turning off the secondary payloads during these periods [6], [24]-[26].

The principal contributors to the attitude control subsystem (ACS)'s pointing error are the orbital position, solar beta angle effect, hardware, and hardware configuration. The spacecraft's magnetically controlled ACS performed correct mode transition as designed, and all six spacecraft performed their on-orbit ACS functions as expected. However, ACS experienced excursions from the required $\pm 5^{\circ}$ pointing accuracy in roll, pitch, and yaw, which sometimes has an impact on GOX sciences data. Fig. 2 shows the FM5 spacecraft attitude on-orbit performance (roll/pitch/yaw pointing error) with respect to the raised spacecraft altitude and beta angle for one-year data since launch. FM5 started performing orbit transfer on May 7 (Day 127),

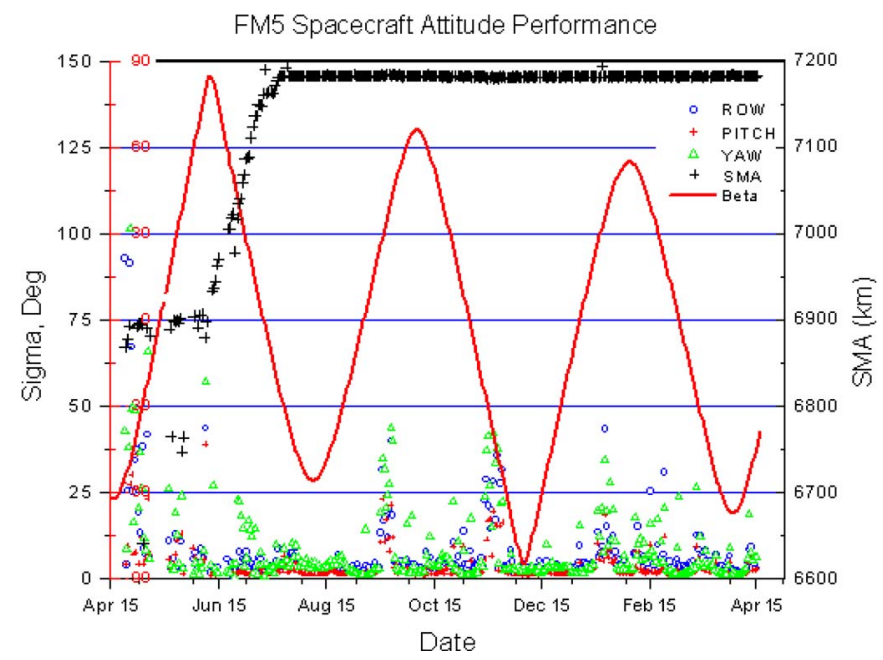

Fig. 2. FM5 spacecraft attitude on-orbit performance (roll/pitch/yaw pointing error) with respect to the raised spacecraft altitude and beta angle for one-year data since launch. 


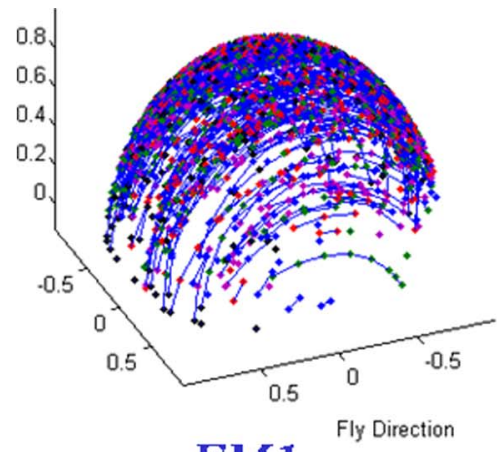

FM1

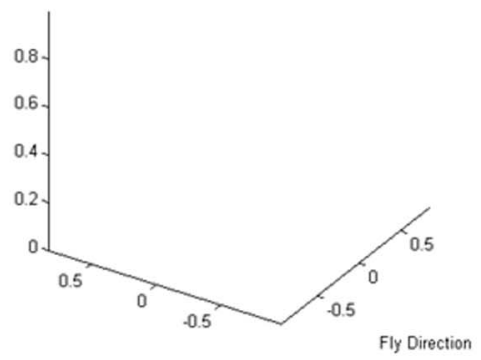

FM4

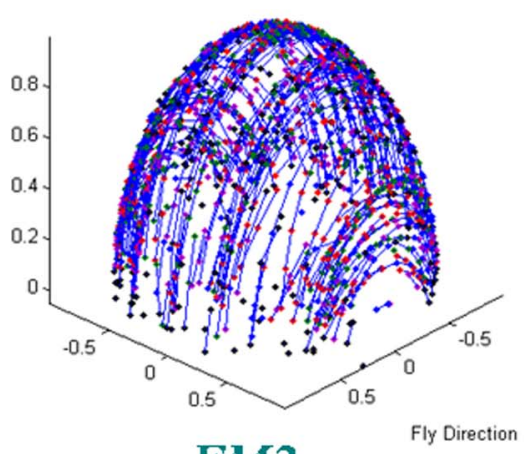

FM2

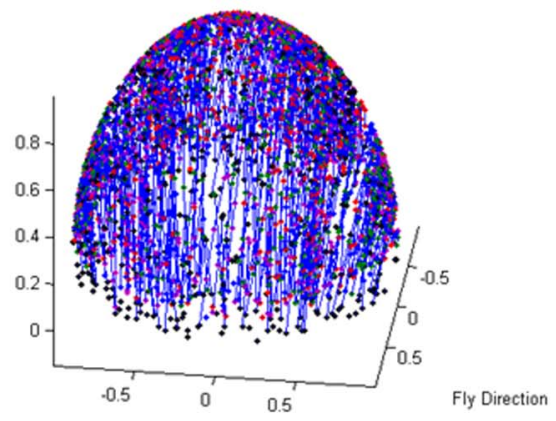

FM5

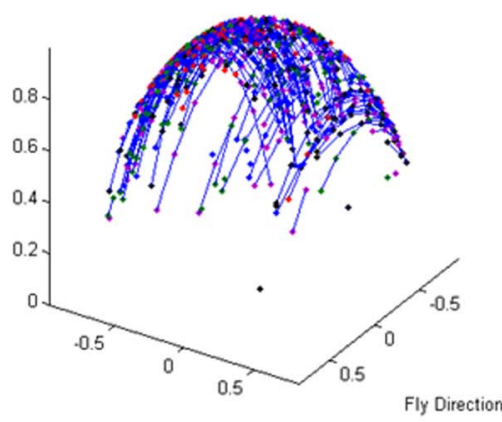

FM3

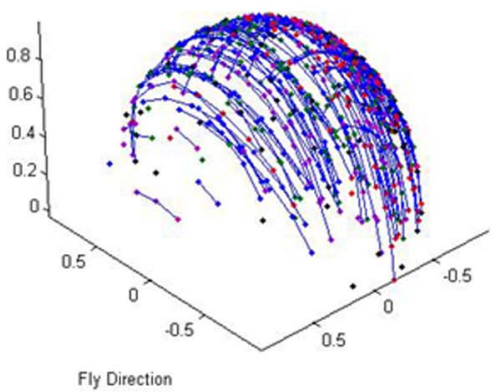

FM6

(a)

GPS Tracking Time of Bus GPSR

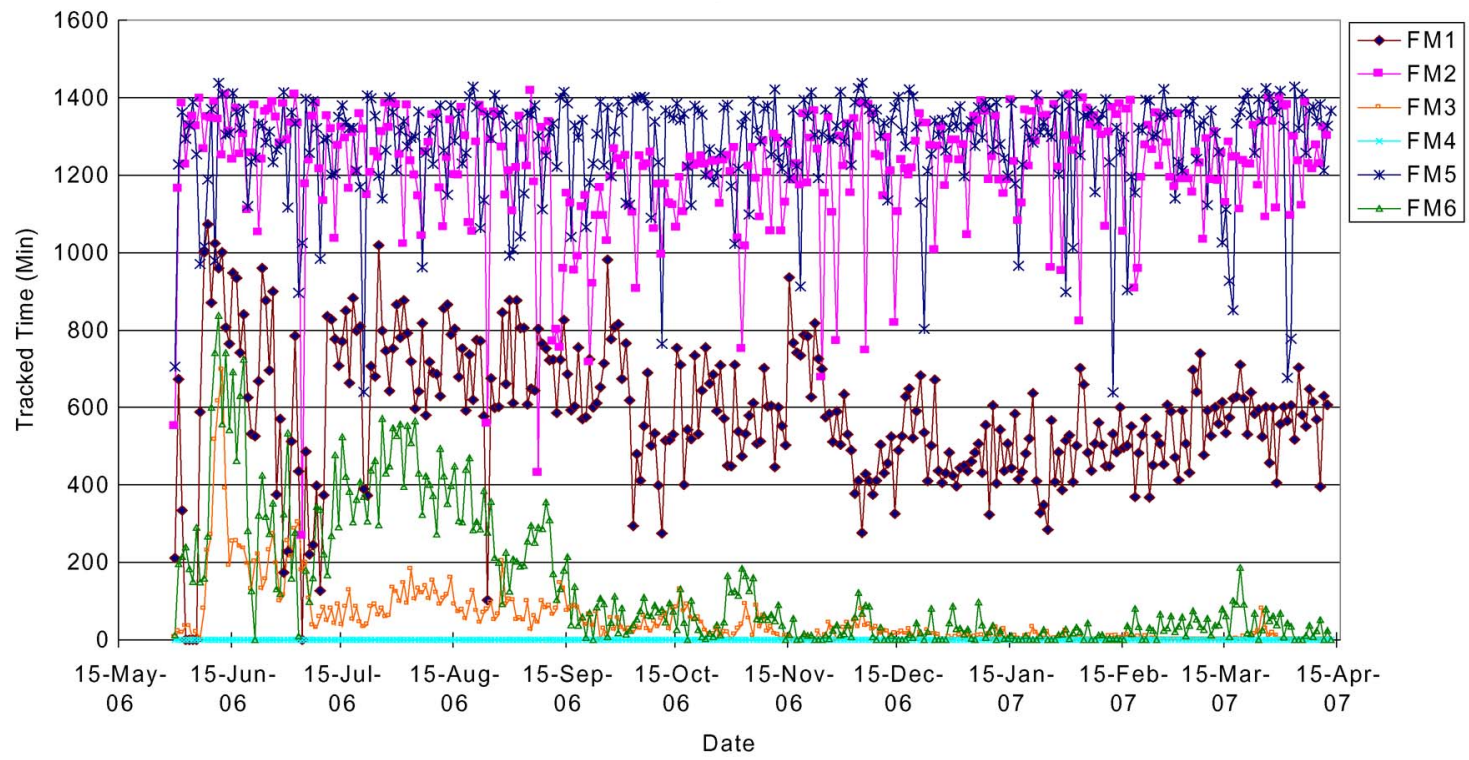

(b)

Fig. 3. (a) GPS 3-D tracking coverage of all six spacecraft Bus GPS Receivers. (b) Number of GPS satellite vehicle tracked statistics for all six spacecraft Bus GPSRs of one-year data after launch.

2006 and arrived at mission orbit on July 19 (Day 200), 2006. From the spacecraft trend data, we observed no major pointing performance improvement when FM5 arrived at its mission orbit. This seems to be the same for the other satellites (FM2, FM4, and FM6). As for pointing knowledge performance, all six spacecraft meet the requirements of both roll and pitch axes. Each spacecraft is equipped with two EHSs to provide roll and pitch attitude information. The EHS is relatively precise compared to coarse sun sensor (CSS) and Magnetometer and can provide attitude information to meet the pointing knowledge requirement. While the attitude information for the yaw axis relies on the coarse attitude sensors (CSS and Magnetometer), it is difficult to meet the pointing knowledge requirement when attitude excursion occurs [6], [14], [25].

The spacecraft Bus GPS Receiver (GPSR) is designed to be the main source of ACS navigation information. However, for six spacecraft, some of the GPSRs rarely work well. For the spacecraft with poorly performed GPSR, the navigation 

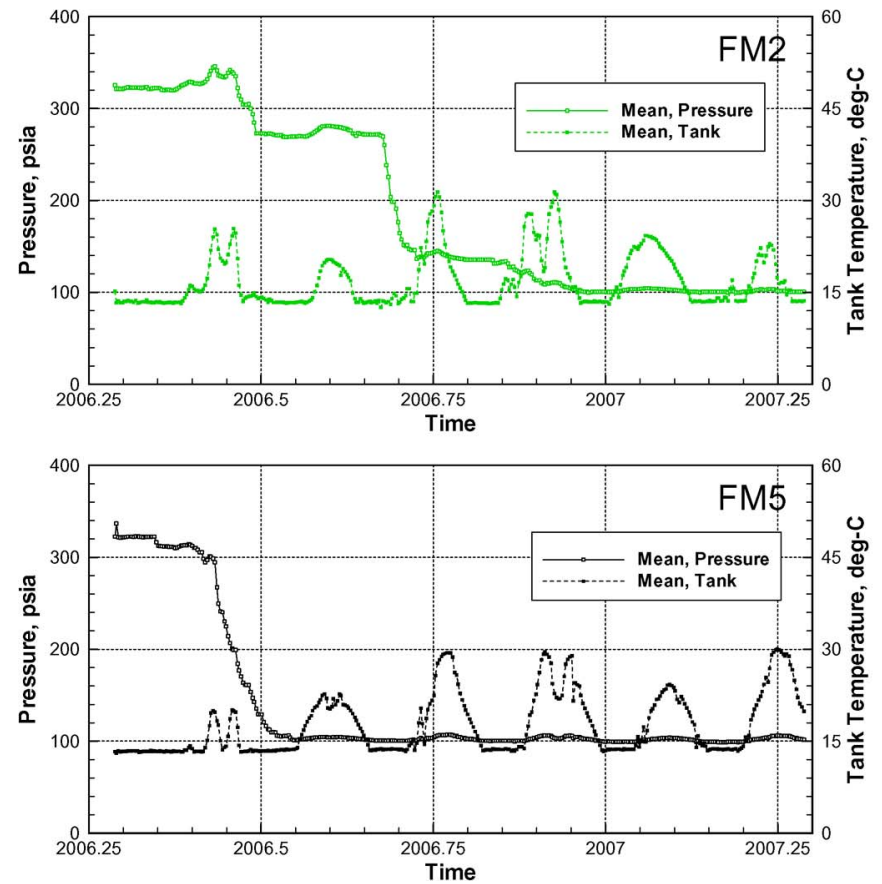
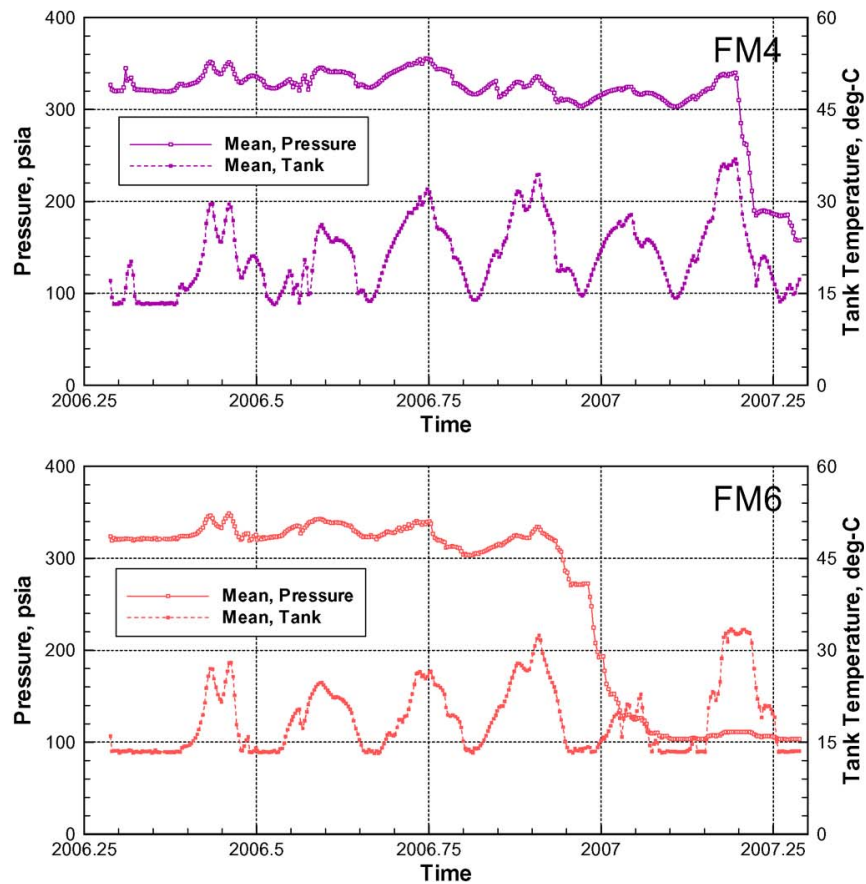

Fig. 4. Trending plots of the tank pressures and temperatures for FM2, FM4, FM5, and FM6 (from April 15, 2006 to April 15, 2007).

information is externally fed by daily uploaded position/ velocity/time (PVT) information from the ground, such that the ACS FSW could propagate the correct PVT and perform the navigation function. As shown in Fig. 3(a), the GPS 3-D on-orbit tracking coverage of all six spacecraft Bus GPSRs was reconstructed on the ground around October and November 2006, for two to three days of tracking data depending on the number of GPS satellite vehicle tracked status. Fig. 3(b) shows the duration of the tracked GPS satellite statistics for all six spacecraft Bus GPSRs for one year. It is shown in Fig. 3 that FM2 and FM5 are fully functional, and any degradation is not shown, unlike FM1, FM3, and FM6, which are only partially functional and have suffered performance degradation since launch. FM4's GPSR has tracked almost no GPS signals from the beginning [6], [14], [25].

The reaction control subsystem is designed for providing the required thrust to transfer the satellites from their parking orbits to the higher altitude mission orbits. The plots in Fig. 4 illustrate the trend of tank pressure and tank temperature for FM2, FM4, FM5, and FM6. When the satellite orbit is in high beta angle situations, direct solar heating will cause a higher temperature level in the satellite. Direct solar heating also influences the tank temperatures and pressures. During the delta- $\mathrm{V}$ burns periods, the tank pressure decreases from 320 psi to around 100 psi. Fig. 4 also shows that the orbit-raising maneuvers were completed for FM5, FM2, and FM6, and the orbit transfer was still in processes for FM4 one year after launch [25].

There is a $40 \%$ power margin on average for each spacecraft observed, based on the one-year trend data. There is also no sensible degradation in the power system on any of the satellites except FM2, which is suffering from an additional $20 \%$ power shortage when the $40 \%$ original margin is taken into account. It is observed that the FM2 maximum power capacity of the solar arrays had been reduced by about 50\% starting on March 1,

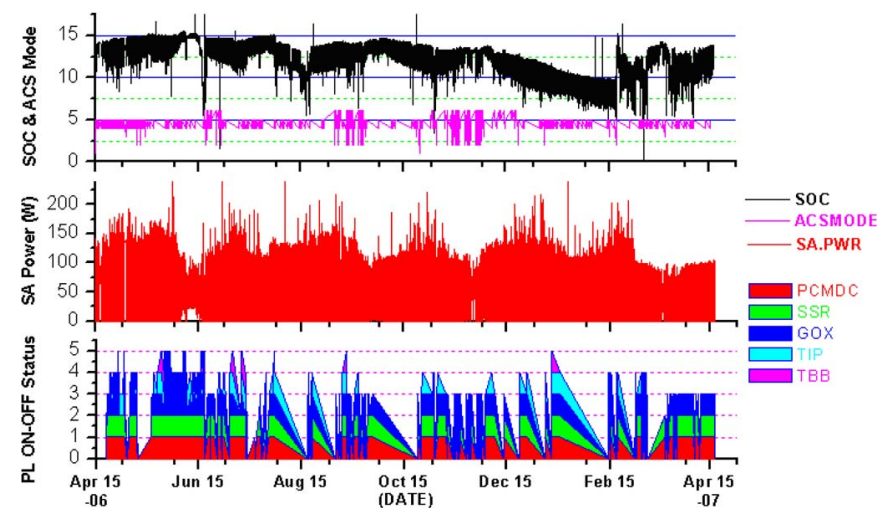

Fig. 5. One-year trend of solar power and battery SOC, ACS mode, and payload on-off status on spacecraft FM2.

2007 [6], [13], [14]. In Fig. 5, we show the one-year trend of solar power and battery state of charge (SOC), ACS mode, and payload on-off status for FM2.

\section{Constellation Deployment Mission Results}

FM2, FM4, FM5, and FM6 have reached their respective mission orbits, and the remaining propellant masses for these four satellites are around $2.0 \mathrm{~kg}$, which is equivalent to $30 \%$ of the full tank capacity. For detailed constellation deployment mission results and associated problems encountered, please refer to another paper submitted to this special issue [25].

\section{GOX Payload On-Orbit Performance Summary}

Table V shows the GOX firmware build (FB) change history since launch. Fig. 6 shows the one-year RF signal-to-noise ratio (SNR) performances of four GOX antennas (POD1, POD2, OCC1, and OCC2) on each GOX payload instrument in FM3 
TABLE V

GOX FB Change History Since Launch

\begin{tabular}{|c|c|c|}
\hline Version & Upload date & Objective \\
\hline FB4.1 & $5 / 18 / 2006$ & An improved atmospheric model for open loop tracking. \\
\hline FB4.2 & $5 / 30 / 2006$ & $\begin{array}{l}\text { 1. Double precision } \mathrm{P} 2 \text { Phase. } \\
\text { 2. To facilitate ionospheric occultation. } \\
\text { 3. Bookkeeping. }\end{array}$ \\
\hline FB4.2.1 & $6 / 29 / 200$ & $\begin{array}{l}\text { 1. To avoid logging unnecessary data and to get more } \\
\text { occultation events. } \\
\text { 2. To make sure that occulting satellites do not get used in the } \\
\text { Navigation solution. }\end{array}$ \\
\hline FB4.3 & $12 / 27 / 2006$ & $\begin{array}{l}\text { 1. Fix bugs such as: azimuth window, rising occultation to end } \\
\text { earlier than at the commanded height, integer cycle slips } \\
\text { during transition from open to closed loop tracking of rising } \\
\text { occultation, halt acquisition and tracking of a particular PRN } \\
\text { 2. Insertion of S4 scintillation parameter for ionosphere study. }\end{array}$ \\
\hline
\end{tabular}

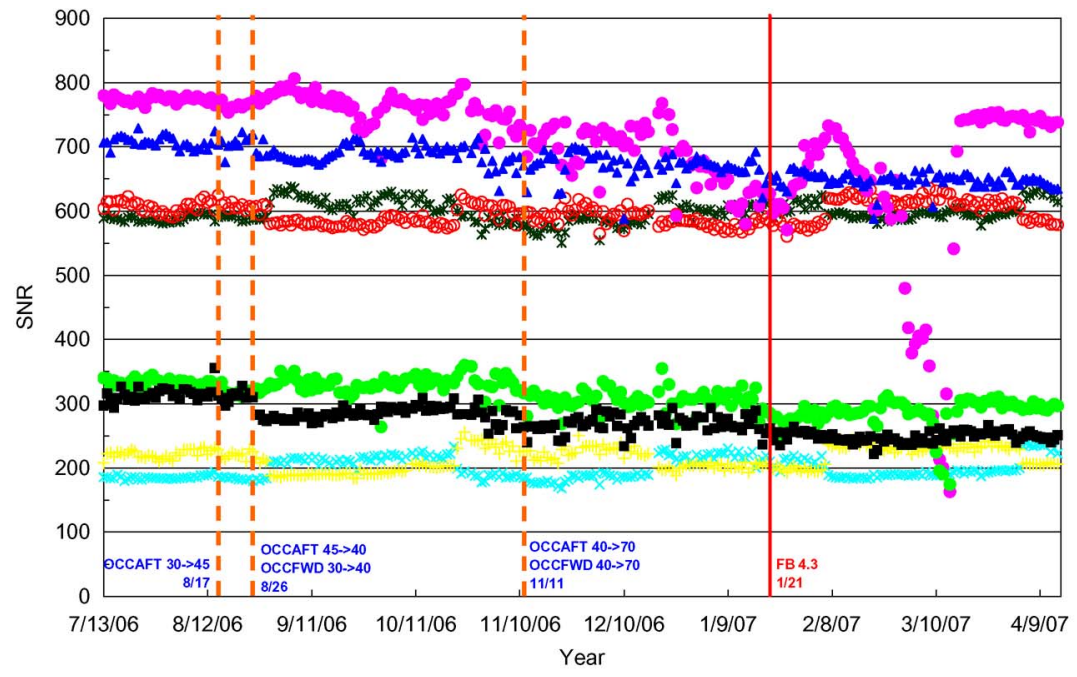

(a)

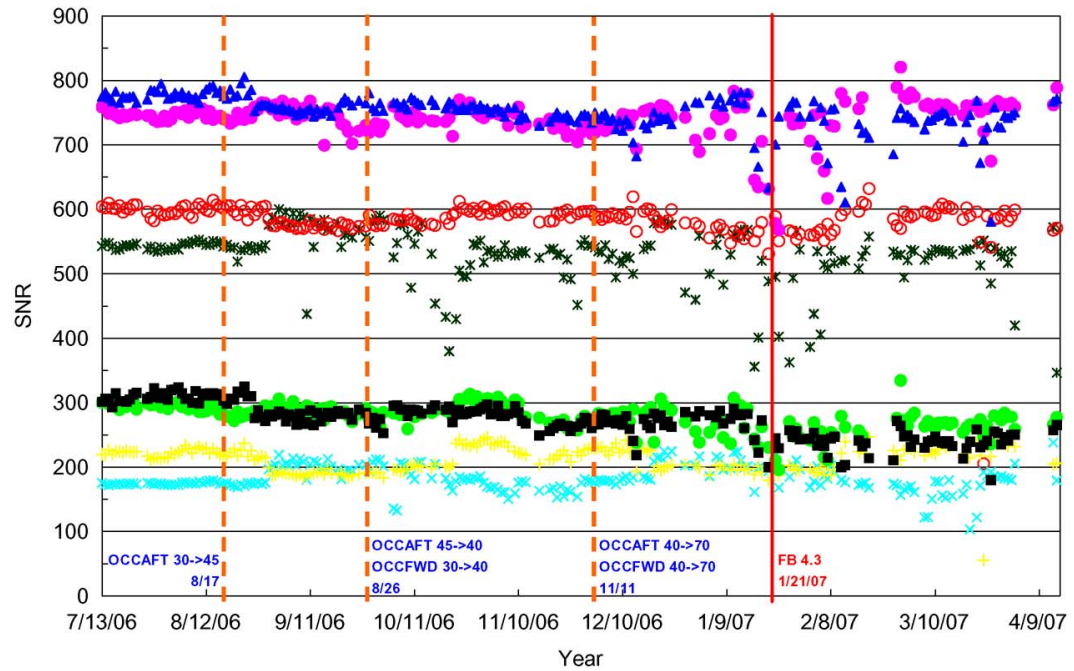

(b)

- OCC1 CASNR $\triangle$ OCC2 CASNR $*$ POD1 CASNR O POD 2 CASNR OCC1 P2SNR — OCC@ P2SNR $\times$ POD1 P2SNR + POD2 P2SNR

Fig. 6. FORMOSAT-3/COSMIC Payload POD \& OCC CA and P2 SNR for (a) FM3 and (b) FM6. "POD" means Precision Orbit Determination Antenna, and "OCC" means Occultation Antenna. 


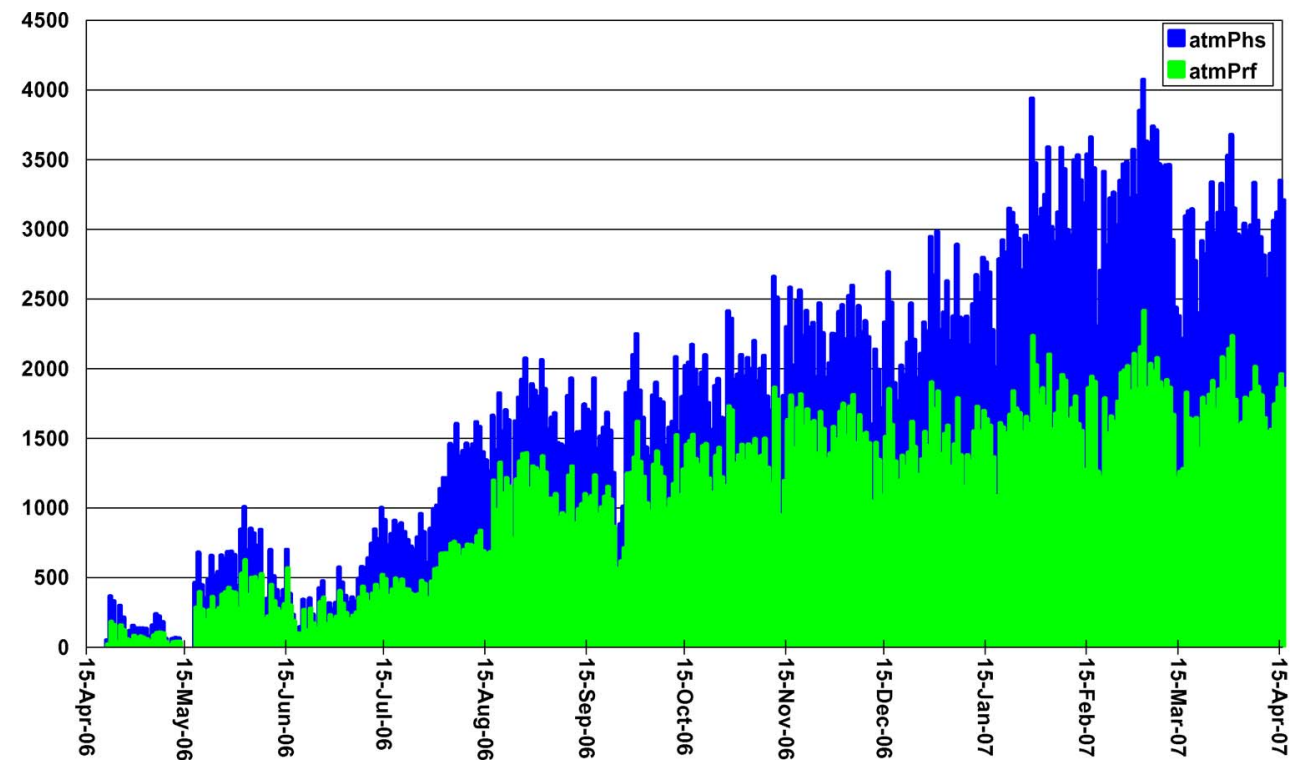

(a) Atmospheric occultation events

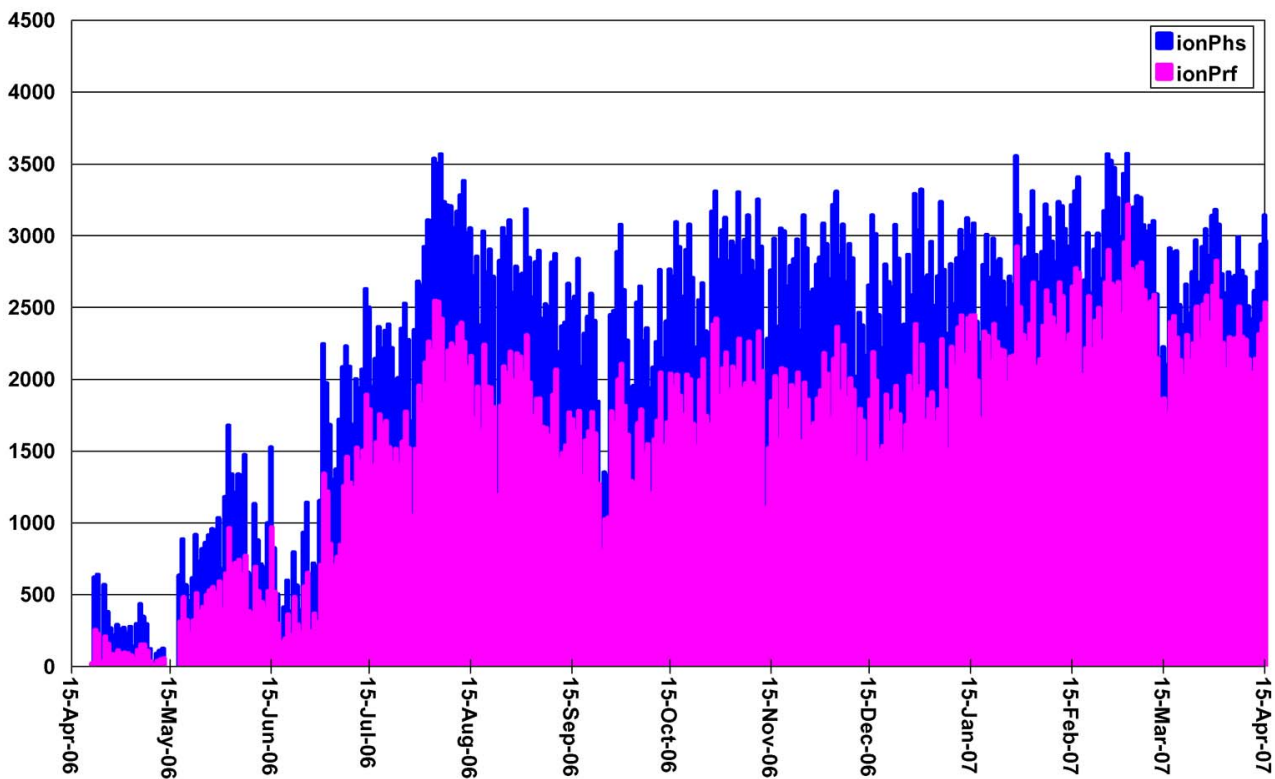

(b) Ionospheric occultation events

Fig. 7. One-year statistics showing the number of daily occultation events for (a) atmosphere profiles one year since launch. (b) Ionosphere profiles of electron density one year since launch. The term "atmprf" means the number of daily atmospheric profiles (atmprf) retrieved since launch. The term "atmphs" means the number of excess phase files generated and also represents the atmospheric RO profiles that can be observed by FORMOSAT-3 satellites in the neutral atmosphere (stratosphere and troposphere); "ionprf and ionphs" indicates ionosphere.

and FM6 spacecraft. In these figures, only data received after July 13 (Day 194), 2006, where FB4.2.1 was uploaded, are shown. The definition of the daily SNR value shown in Fig. 6(a) and (b) is the bottom limit of the top 90\% SNR value of all the tracked GPS satellites' signal SNR values received by that particular antenna either in coarse/acquisition or precision (P2) signal code. Following the uploading of FB version 4.3 (FB4.3) of the GOX payload to all the six spacecraft, from December 2006 onward, the trends of the GOX payload's (SNR) data did not show any sign of degradation at all from the available GPS RO science data. The SNR value of OCC1 on spacecraft FM3 shown in Fig. 6(a) did show a decreasing tendency; the value drops very rapidly when the spacecraft is at a high beta angle. We observe that the SNR value returns to its normal value when
GOX temperature is below $40{ }^{\circ} \mathrm{C}$ and spacecraft FM3 leaves the high beta angle. The decreasing of GOX SNR on FM6, as shown in Fig. 6(b), is related to the reboot-loop issue and will be addressed later [6].

\section{E. GPS RO Profile Statistics After One Year}

Fig. 7 shows the number of daily atmospheric profiles (atmprf) and ionospheric profiles (ionprf) retrieved since launch. The term "atmphs" in Fig. 7 indicates the number of excess phase files that are generated and also represent the atmospheric RO profiles that can be observed by FORMOSAT-3 satellites in the neutral atmosphere (stratosphere and troposphere). The "ionphs" in Fig. 7 indicates ionosphere. The new 

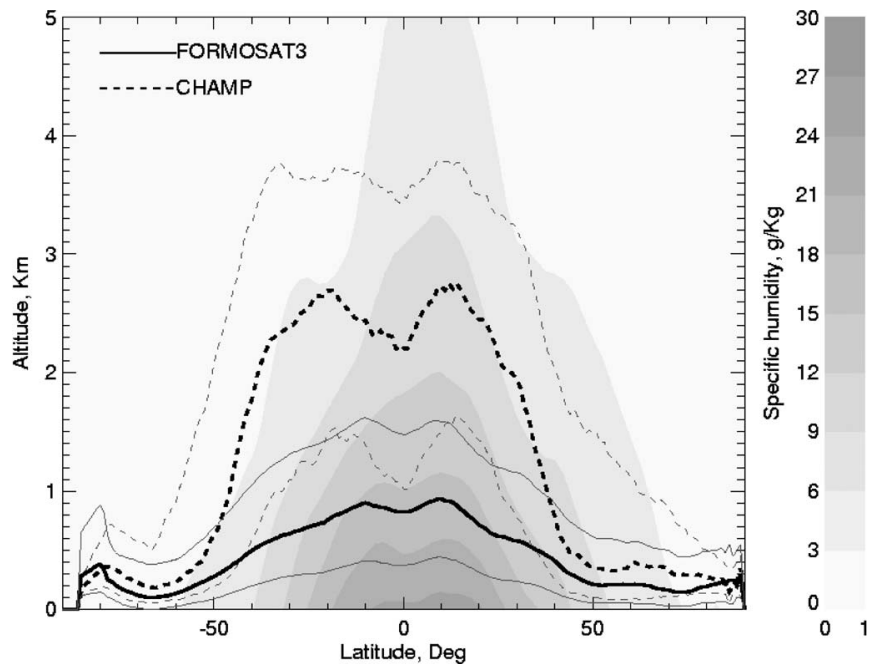

Fig. 8. Comparison of the lowest altitude penetration of RO events versus latitude for FORMOSAT-3/COSMIC and CHAMP. The data used was taken from January 1 to May 10, 2007. The bold solid line is the median value of the lowest altitude penetration for FORMOSAT-3. The solid line above and under the median value are respectively the $75 \%$ and $25 \%$ statistical average value of the distributed data for FORMOSAT-3. Same for CHAMP for bold dashed and dashed lines. The gray area plot is the water vapor specific humidity distribution in altitude and latitude. The specific humidity data are obtained from an NCEP model of March 1968 to 1996.

open-loop FB version 4.2.1 (FB4.2.1) was uploaded to the GOX payload in July 2006, which caused a large jump in the daily RO profile numbers for August 2006. From Fig. 7, it is clear that $\sim 37 \%$ of the total events cannot be retrieved to neutral vertical atmosphere profiles. This is true for $\sim 25 \%$ of ionospheric profiles. Fig. 7 also shows that the FORMOSAT-3/COSMIC mission has processed 1800 high-quality neutral atmospheric sounding profiles per day, which is more than the total number of worldwide radiosondes launched ( $\sim 900$ mostly over land) per day and 2500 good ionospheric sounding profiles per day. The occultation events collected by the current FORMOSAT-3/ COSMIC constellation have realized $\sim 70 \%$ of the mission goal of 2500 events per day so far [13]-[15], [24].

\section{F. Penetration of RO Profiles in FORMOSAT-3/COSMIC Into the Lower Troposphere}

UCAR's research group contributes continuous improvements to the RO technique. The phase-locked loop technique employed in earlier RO missions was replaced by a novel openloop technique for the FORMOSAT-3/COSMIC mission. Most of the occultation measurements can now penetrate to altitudes as low as $1 \mathrm{~km}$ above the Earth's surface. It was estimated that about $70 \%$ of the COSMIC soundings penetrate below $1 \mathrm{~km}$ over the sea surface in the tropics, with about $90 \%$ reaching this depth at high latitudes [12]-[14], [16]-[18]. Fig. 8 compares the lowest altitude penetration of RO profiles versus latitude for FORMOSAT-3/COSMIC and CHAMP. The data were taken from January 1 to May 10, 2007. The bold solid line in Fig. 8 is the median value of the lowest altitude penetration for FORMOSAT-3/COSMIC. The solid lines above and below the median value are, respectively, the $75 \%$ and $25 \%$ statistical average values of the distributed data for FORMOSAT- 3 . The bold dashed line is the median value of the lowest altitude penetration for CHAMP. The dashed lines above and below the median value are the $75 \%$ and $25 \%$ statistical average values of the distributed data for FORMOSAT-3. The gray area plot is the water vapor specific humidity distribution with respect to altitude and latitude. The specific humidity data are obtained from an NCEP analysis averaged from March 1968 to 1996 [18], [24].

\section{Operational Challenges And PERFORMANCE ENHANCEMENTS}

Below are highlights of some major operations challenges encountered and enhancements accomplished during the launch and early orbit and constellation deployment phases [6], [24], [25].

\section{A. Spacecraft Bus GPS Receiver Issue}

The spacecraft Bus GPSR of FM1, FM3, FM4, and FM6 could not reliably acquire and lock onto the signals from the GPS constellation, as shown in Fig. 3. The Bus GPSR sometimes provides erroneous data, causing problems in the TIP payload time stamping, ACS navigation processing, and the onboard timing system. These data problems cause the navigation to output erroneous data and result in erratic attitude excursion behaviors on the spacecraft. The issue has been resolved by inhibiting any state vector solution from the Bus GPSR and then commanding four known state vectors daily to each corresponding spacecraft from SOCC. The state vector is obtained from the GOX payload. NSPO picked FM5 and FM2 as the first two spacecraft to be raised from their parking orbit, since their GPS receivers were behaving nominally. This allowed the team to perform orbit determination using the data from the spacecraft Bus GPS receiver. As for the other four spacecraft (FM1, FM3, FM4, and FM6), NSPO has modified the thrusting procedure to include GOX operations as part of burn activities [24]-[26].

\section{B. High Beta Angle Effect}

There were thermal anomalies related to orbital high beta angles. At high beta angles, the spacecraft were in constant sunlight. This causes the EHS temperature to become higher than expected. In addition, the battery pressures rose higher and closer to the specified limit during this time period. To solve this issue, TIP and TBB were turned off when the beta angle was higher than $60^{\circ}$. To resolve the battery pressure issue, the charge rate was fine-tuned to maintain the battery within the normal pressure limit through frequent monitoring and commanding. The power control flight software was subsequently modified to include a new battery overpressure protection function, and this was successfully uploaded early in 2007. Currently, the battery pressure is being maintained at nominal condition autonomously [6], [13]-[15].

\section{Spacecraft FM2 Power Shortage}

As shown in Fig. 5, generally, the average solar power falls into $140-150 \mathrm{~W}$ with a $200-\mathrm{W}$ solar array power capacity in design. Actual flight experience shows that battery capacity is 
(days)

\begin{tabular}{|c|c|c|c|}
\hline S/C ID & GOX & TBB (all on) & TIP \\
\hline FM1 & 272 & $220(27)$ & 244 \\
\hline FM2 & 248 & $14(4)$ & 173 \\
\hline FM3 & 287 & $232(14)$ & 246 \\
\hline FM4 & 301 & $224(1)$ & 244 \\
\hline FM5 & 301 & $217(12)$ & 246 \\
\hline FM6 & 276 & $123(7)$ & 192 \\
\hline
\end{tabular}

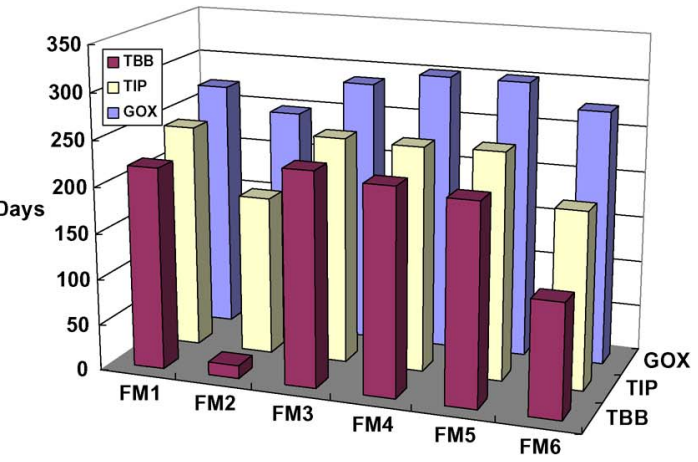

Fig. 9. One-year payload (GOX/TBB/TIP) power-on statistics.

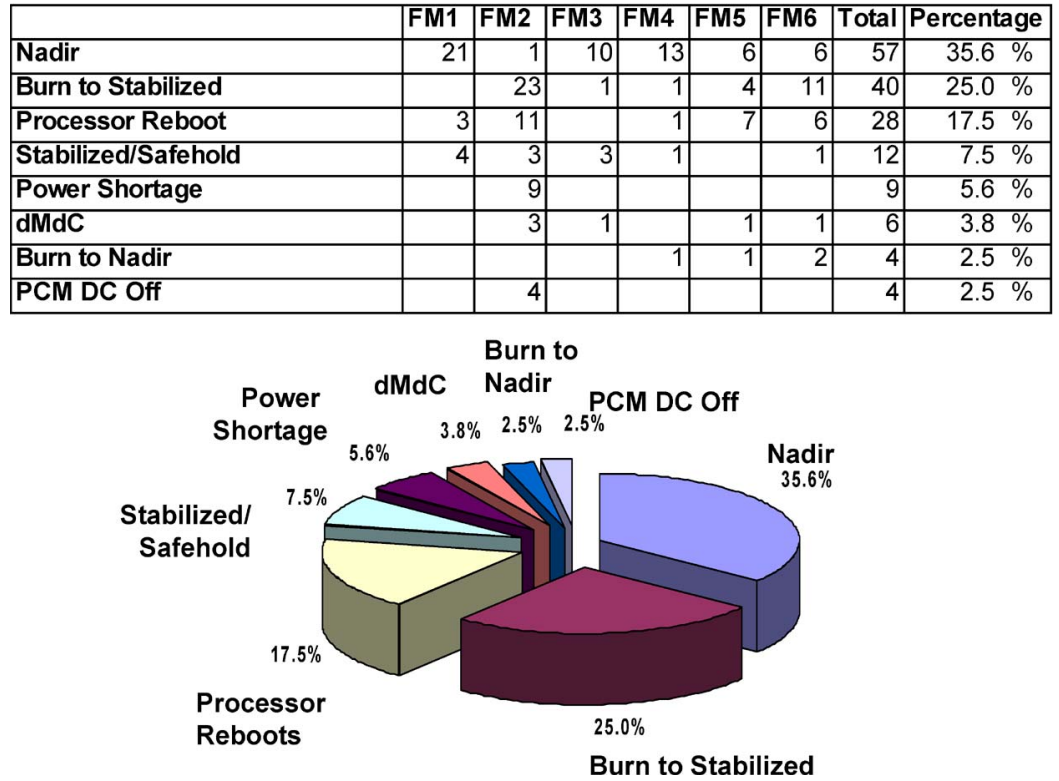

Fig. 10. One-year statistical results of payload power-off phenomenon on all six spacecraft. During the one year operation, the causes of payload off are categorized to: (1) Nadir mode due to attitude excursion; (2) Stabilized mode after thrust burns; (3) Processor reboot/resets; (4) Entrance to stabilized/safehold mode; (5) FM2 power shortage; (6) Derivative of Battery Molecular to Charge (dMdC) anomaly; (7) Nadir mode after thrust burns so that spacecraft enter into power contingency; and (8) Power Control Module (PCM) Direct Current (DC) Off anomaly.

greater than a specified value in typical normal operation. The maximum battery capacity or SOC can be as high as $15 \mathrm{Ah}$ after being charged. The peak power-tracking scheme can maintain the solar array at its maximum power output, but it is restricted by maximum battery charge current as well. On March 1, 2007, the operations team observed that the maximum power capacity of the solar arrays had been reduced by about $50 \%$. FM 2 had experienced a sudden solar array power shortage. An investigation of this power shortage anomaly resulted in a recovery plan to operate the GOX at a reduced duty cycle. Currently, FM2 is supporting the GOX at $\sim 70 \%$ duty cycles with the secondary payloads remaining off at all times [13]-[15].

\section{Payload Power-On/Off Statistics}

The one-year payload (GOX/TBB/TIP) power-on data statistics are shown in Fig. 9. We can see that the spacecraft FM4 and FM5 have the GOX payload on most days. FM2 has the least GOX power due to the power shortage already mentioned. FM6 has the second-worst GOX payload power-on due to the
GOX reboot-loop issue addressed below. TIP and TBB power on also show the same trend. The one-year statistical results of payload power-off phenomenon on all six spacecraft are shown in Fig. 10, and the data are analyzed from Day 175 of 2006 to Day 105 of 2007. Before Day 175 of 2006 , the $8^{\circ}$ off angle in EHS has not been fixed, and the GOX has not been on for continuous $24 \mathrm{~h}$. We also exclude the action events undertaken by the operations team, such as FSW and common spacecraft database upload, resetting of some processors, etc. The events for payload off will eventually reduce the GOX RO science data volume. The purpose of gathering these statistics is to determine the causes of payload off. During the oneyear operation, the causes of payload off are categorized in the following: 1) nadir mode due to attitude excursion (35.6\%); 2) stabilized mode after thrust burns (25\%); 3) processor reboot/resets $(17.5 \%)$; 4 ) entrance to stabilized/safehold mode $(7.5 \%)$; 5) FM2 power shortage $(5.6 \%)$; 6) derivative of battery molecular to charge anomaly $(3.8 \%) ; 7)$ nadir mode after thrust burns, so that spacecraft enter into power contingency; and 8) power control module direct current off anomaly. Fig. 5 


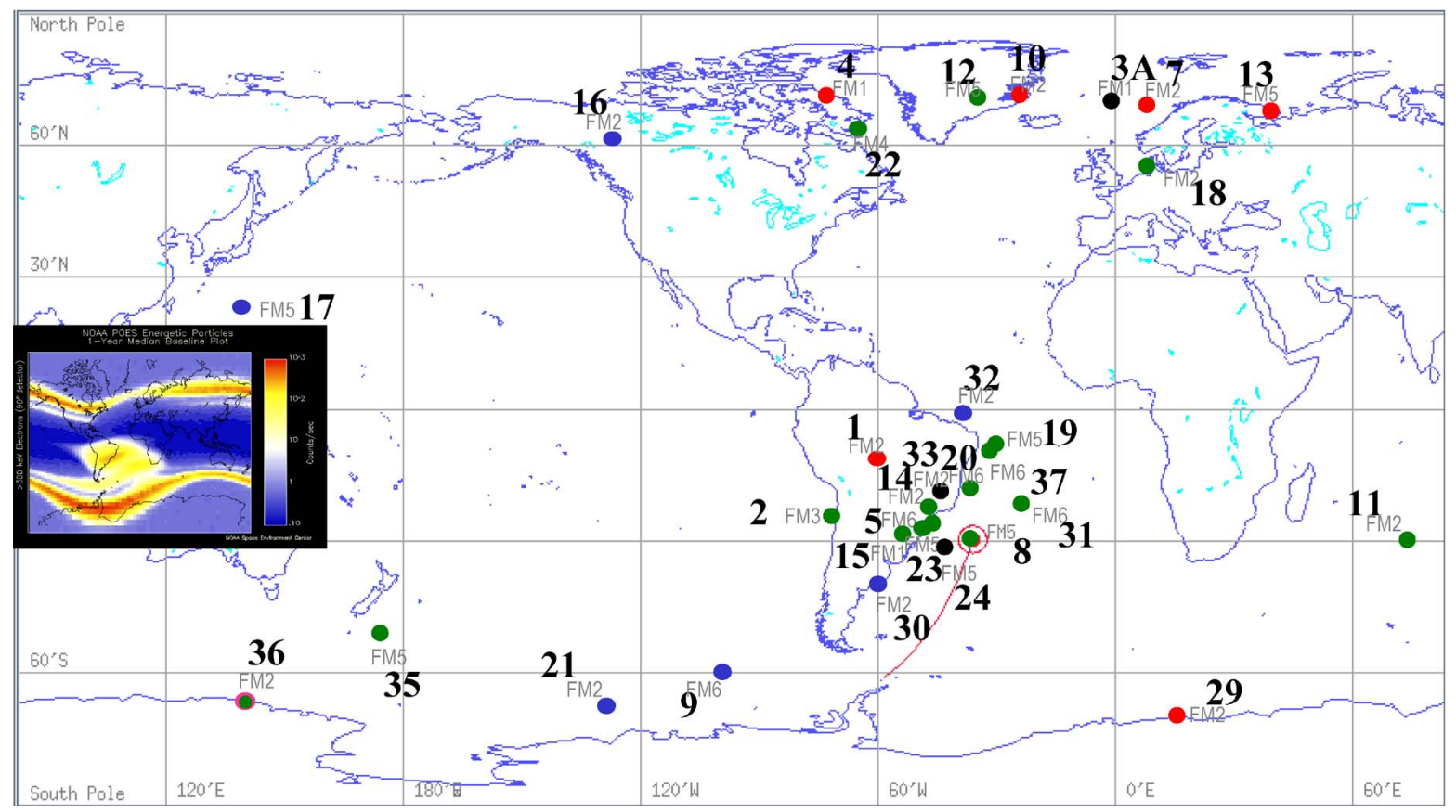

Fig. 11. Geographic location of the spacecraft reset/reboot events one year after launch, and comparison with the NOAA POES satellite's one-year $>300-\mathrm{kEV}$ energetic particle chart (courtesy of NOAA).

shows that the top three causes are attitude excursions, stabilized mode after thrust burn, and processor reboot/reset and that they have occupied around three quarters of all payload poweroff events [13]-[15].

\section{E. Computers Reset/Reboot}

A total of 32 out of 37 spacecraft resets and reboots, including flight computer (FC), battery charge regulator (BCR), and attitude control electronics (ACE), have been observed through May 11, 2007 since launch. Fig. 11 shows the projected geographic locations of these reset/reboot events on the Earth after one year in orbit. The black dot in Fig. 11 represents the location of the spacecraft where master reset occurs; the red dots represent where the reboot occurs on FC of the spacecraft; the blue dots are for BCR; and the green dots are for ACE. Fig. 11 also includes NOAA's Polar Operational Environmental Satellite (POES)'s one-year $>300-\mathrm{keV}$ energetic particle chart for comparison (courtesy of NOAA). Further investigation shows that most of the time and geolocations the spacecraft anomalies occurred are closely correlated to the space radiation environment. Single event effects in the South Atlantic anomaly region and the polar region are identified as the most probable root cause. No spacecraft performance has been degraded by these anomalies [13]-[15], [24].

\section{F. GOX Payload Reboot Loop}

Two kinds of GOX payload reboot-loop anomaly event were observed. The first kind is that the GOX instrument will automatically reboot and recover itself when there is no navigation solution for 15 min. This has happened on FM1 and FM6. For the second kind, consecutive reboots have occurred every 15 min and cannot be recovered automatically or by a power cycle command. FM6 had the latter kind of reboot anomaly in February, April, and July of 2007. The cause was preliminarily identified as the low SNR of the navigation antenna when the spacecraft entered into beta angle between $0^{\circ}$ and $-30^{\circ}$. A new FB version 4.4 (FB 4.4) was loaded in June 2007, enabling GOX to select the other healthy antenna as the navigation antenna, which is in the forward fly direction. The reboot loop has since ceased [6], [13]-[15], [24].

\section{G. SSR Data Overflow}

The solid state recorder (SSR) data storage only allocated $32 \mathrm{MB}$ for GOX-B out of 128-MB total memory. During the constellation deployment phase, it was always possible to accumulate GOX data more than $32 \mathrm{MB}$ before dumping the data to the ground. When the data overflow took place, it always came along with the data wrapping (disorder) because the $32 \mathrm{MB}$ was not an integer numbers of the science data packet size, and the write pointer of the SSR would pass over the read pointer when data overflow occurred. To resolve this issue, the operations team narrowed the GOX's field of view to control the data volume. When the spacecraft orbit planes separated and the availability of ground pass became better, the team opened up the GOX's field of view and scheduled the dump to prevent the occurrence of SSR data overflow. The autoscheduling tool was generated to optimize the ground station utilization so as to minimize data dumped. After all spacecraft reach the final constellation with the orbit phasing under control, the loss of data due to SSR overflow no longer occurred [6].

\section{H. GOX Data Gapping Issue}

The GOX data gapping problem is that $29 \%$ of RO science data have gapping issues. After investigating questionable raw 
data, we found that a similar data dropout pattern has been observed in the ground End-To-End (ETE) tests. However, the on-orbit gapping issue is much worse than that found in the ETE tests. Through several analyses and tests, it was concluded that when dumping the stored spacecraft data and science data simultaneously, the data dropouts are the worst. The operations team made these two data dumps separately to recover the data dropout issue, and rescued $70 \%$ of the lost data. Even when the science data are downloaded alone, the data dropouts still cause $8 \%$ of data gapping. A typical dump has a very small amount of data dropouts $(\sim 0.04 \%)$, but it actually causes $8 \%$ of RO data gapping. The remedy for reducing data gapping is to dump the same science data twice. Eventually, these two dumps will not drop the same data packets, so we can make up any dropout. The saved data from double dumps are only about $0.04 \%$ of the whole data volume, but the RO data will increase $8 \%$. Hence, even though double dumps increase local data storage and double the data transfer time from ground station to the data analysis center, they are still worthwhile. [6], [13], [14], [24].

\section{Assimilation in Numerical Weather Prediction Models}

The ECMWF and the NCEP are assimilating the RO data into their real-time operational forecast systems. Preliminary results have shown that the FORMOSAT-3/COSMIC data improve the prediction of typhoon/hurricane tracks, including when and where they will hit land. ECMWF shows that the FORMOSAT-3/COSMIC measurements improve the accuracy of their forecasts by about $11 \%$ in the Southern Hemisphere at $100 \mathrm{mb}$. More than $70 \%$ of the data have a latency of less than $3 \mathrm{~h}$ as reported by ECMWF [12], [20]. NCEP's studies have shown that their forecasts have significantly improved in accuracy when the FORMOSAT-3/COSMIC data are assimilated into the system [12], [21]. Taiwan's CWB has reported that the contribution of FORMOSAT-3/COSMIC has advanced their prediction capabilities by two years [27].

\section{J. Impact on Ionospheric Space Weather Structure}

The launch of the innovative FORMOSAT-3/COSMIC satellite constellation has ushered in a new era of studying the effects of ionospheric space weather [28], [29]. Taking advantage of dense global 3-D observation coverage, a new ionospheric structure and some important atmosphere-ionosphere coupling theories have been proposed and verified based on observations made [28]. A newly discovered ionospheric structure, namely, the low-latitude ionospheric plasma cave, shows a depleted plasma region underneath the region of strongest plasma concentration [28]. Meticulous observation of this new ionospheric structure will certainly improve our fundamental understanding of ionospheric dynamics and will be beneficial in evaluating ionospheric effects on the space environment and on communications through space. The data provided by FORMOSAT-3/COSMIC have also uncovered a unique ionospheric structure, which could possibly be associated with tropical rainstorms and is proposed to be formed by an atmosphere-ionosphere coupling process [29]. FORMOSAT-3/
COSMIC's capability to observe vertical plasma distribution across a 24-h period led to the verification of a plausible physical mechanism of this unique ionospheric structure. The influences of the tropical rainstorms and atmospheric weather have been included as considerations for space weather [28], [29].

\section{CONCLUSiON}

We have summarized the satellite constellation system performance after one year in orbit. All six spacecraft are in good condition after six satellite years of operation and were on their way toward the final constellation. With the development and application of the open-loop tracking technique by JPL and UCAR, the quality, accuracy, and lowest penetration altitude of the RO sounding profiles have been improved in comparison to previous RO missions. As of April 15, 2007, about 1800 high-quality soundings were being retrieved daily on a global basis. The constellation spacecraft system on-orbit performance will be constantly monitored, tracked, evaluated, and enhanced by NSPO's operations team in the future. It is anticipated that an increasing number of global operational centers will use FORMOSAT-3/COSMIC data operationally for the years to come.

\section{ACKNOWLEDGMENT}

The authors would like to thank the spacecraft team, particularly M.-S. Chang, A. Chang, R. Lo, and Y. Hsu, for providing one-year statistical trend data in various subsystems. The authors would also like to thank Dr. C. H. Lin of NSPO for summarizing the ionosphere research portion.

\section{REFERENCES}

[1] R. A. Anthes, C. Rocken, and Y. H. Kuo, "Application of COSMIC to meteorology and climate," Terrestrial, Atmos. Ocean. Sciences (TAO), vol. 11, no. 1, pp. 115-156, Mar. 2000.

[2] T. P. Yunck, C. H. Liu, and R. Ware, "A history of GPS sounding," Terrestrial, Atmos. Ocean. Sciences (TAO), vol. 11, no. 1, pp. 1-20, Mar. 2000.

[3] Y.-H. Kuo, T.-K. Wee, S. Sokolovskiy, C. Rocken, W. Schreiner, D. Hunt, and R. A. Anthes, "Inversion and error estimation of GPS radio occultation data," J. Meteorol. Soc. Jpn., vol. 82, no. 1B, pp. 507-531, 2004.

[4] A. Rius, G. Ruffini, and A. Romeo, "Analysis of ionospheric electron density distribution from GPS/MET occultations," IEEE Trans. Geosci. Remote Sens., vol. 36, no. 2, pp. 383-394, Mar. 1998.

[5] J. M. Pallares, G. Ruffini, and L. Ruffini, "Ionospheric tomography using GNSS reflections," IEEE Trans. Geosci. Remote Sens., vol. 43, no. 2, pp. 321-326, Feb. 2003.

[6] C.-J. Fong, N. L. Yen, C.-H. Chu, S.-K. Yang, W.-T. Shiau, C.-Y. Huang, S. Chi, S.-S. Chen, Y. A. Liou, and Y. H. Kuo, "FORMOSAT-3/COSMIC spacecraft constellation system, mission results, and prospect for followon mission," Terr., Atmos. Ocean. Sci. (TAO), vol. 20, no. 1, Jan. 2009.

[7] Y.-A. Liou, A. G. Pavelyev, S.-F. Liu, A. A. Pavelyev, N. Yen, C.-Y. Huang, and C.-J. Fong, "FORMOSAT-3/COSMIC GPS radio occultation mission: Preliminary results," IEEE Trans. Geosci. Remote Sens., vol. 45, no. 11, pp. 3813-3826, Nov. 2007. DOI: 10.1109/TGRS. 2007.903365.

[8] TACC Website. [Online]. Available: http://tacc.cwb.gov.tw/en/index.htm

[9] CDAAC Website. [Online]. Available: http://cosmic-io.cosmic.ucar.edu/ cdaac/index.html

[10] R. Anthes, "Welcome to a new era!" in Proc. FORMOSAT-3/COSMIC Workshop-Early Results IOP Campaign, Taipei, Taiwan, Nov. 28Dec. 1, 2006 
[11] C.-H. Chu, S.-K. Yang, C.-J. Fong, N. Yen, T.-Y. Liu, W.-J. Chen, D. Hawes, Y.-A. Liou, and Y.-H. Kuo, "The most accurate and stable spaceborne thermometers-FORMOSAT-3/COSMIC constellation," in Proc. 21st Annu. AIAA/USU Conf. Small Satell., Logan, UT, Aug. 13-16, 2007, vol. SSC07-VII-1.

[12] R. A. Anthes, P. A. Bernhardt, Y. Chen, L. Cucurull, K. F. Dymond, D. Ector, S. B. Healy, S.-P. Ho, D. C. Hunt, Y.-H. Kuo, H. Liu, K. Manning, C. McCormick, T. K. Mehan, W. J. Randel, C. Rocken, W. S. Schreiner, S. V. Sokolovskiy, S. Syndergaard, D. C. Thompson, K. E. Trenberth, T. K. Wee, N. L. Yen, and Z. Zeng, "The COSMIC/ FORMOSAT-3 mission: Early results," Bull. Amer. Meteorol. Soc. (BAMS), vol. 89, no. 3, pp. 313-333, Mar. 2008. DOI: 10.1175/BAMS89-3-313.

[13] C.-J. Fong, C. Y. Huang, V. Chu, A. Shiau, E. Yang, N. Yen, S. S. Chao, D. Hawes, Y.-H. Kuo, Y.-A. Liou, and S. Chi, "Mission results from FORMOSAT-3/COSMIC constellation system," presented at the AIAA SPACE Conf. Expo., Long Beach, CA, Sep. 18-20, 2007, Paper No. AIAA-2007-6086.

[14] C.-J. Fong, C. Y. Huang, V. Chu, N. Yen, Y.-H. Kuo, Y.-A. Liou, and S. Chi, "Mission results from FORMOSAT-3/COSMIC constellation system," J. Spacecr. Rockets, 2008, to be published.

[15] C.-J. Fong, N. Yen, S. K. Yang, S. S. Chen, and S. Chi, "GPS radio occultation and mission results from FORMOSAT-3/COSMIC spacecraft constellation," in Proc. 3rd Int. Conf. Recent Advances Spacecraft Technol., Istanbul, Turkey, Jun. 14-16, 2007, pp. 748-753. DOI: 10.1109/RAST.2007.4284093.

[16] S. Sokolovskiy, C. Rocken, D. Hunt, W. Schreiner, J. Johnson, D. Masters, and S. Esterhuizen, "GPS profiling of the lower troposphere from space: Inversion and demodulation of the open-loop radio occultation signals," Geophys. Res. Lett., vol. 33, no. 14, p. L14 816, Jul. 2006. DOI: 10.1029/2006GL026112.

[17] W. Schreiner, C. Rocken, S. Sokolovskiy, S. Syndergaard, and D. Hunt, "Estimates of the precision of GPS radio occultations from the COSMIC/FORMOSAT-3 mission," Geophys. Res. Lett., vol. 34, no. 4, Feb. 2007. L04 808.

[18] C.-Y. Huang, C. Z. Cheng, P. H. Lin, C. J. Fong, J. Wicker, and C. C. Hsiao, "Radio occultation retrieval of atmospheric profiles in the FORMOSAT-3/COSMIC mission: Current status," Terr., Atmos. Ocean. Sci. (TAO), vol. 20, no. 1, Jan. 2009.

[19] K. W. Manning and Y. H. Kuo, "Using COSMIC refractivity profiles in an evaluation of Antarctic forecast models," in Proc. 1st Formosat-3/ COSMIC Data Users Workshop, Boulder, CO, Oct. 16-18, 2006.

[20] S. Healy, "Assimilation of GPS radio occultation measurements at ECMWF," European Centre for Medium-range Weather Forecasts (ECMWF) Newsletter, Spring 2007. No. 111.

[21] "COSMIC data to be assimilated operationally at NOAA," Joint Center for Satellite Data Assimilation (JCSDA) Quarterly, Mar. 2007. No. 18.

[22] COSMIC Website. [Online]. Available: http://www.cosmic.ucar.edu/

[23] FORMOSAT-3 Website. [Online]. Available: http://www.nspo.org.tw/ 2005e/projects/project3/

[24] C.-J. Fong, N. Yen, V. Chu, S. S. Chen, and S. Chi, "Operations challenges from the FORMOSAT-3/COSMIC constellation for global Earth weather monitoring," in Proc. IEEE Aerosp. Conf., Big Sky, MT, Mar. 3-10, 2007, pp. 1-14. DOI: 10.1109/AERO.2007.352986.

[25] C.-J. Fong, A. Shiau, T. Lin, T.-C. Kuo, C.-H. Chu, S.-K. Yang, N. Yen, S. S. Chen, C.-Y. Huang, Y.-H. Kuo, Y.-A. Liou, and S. Chi, "Constellation deployment for FORMOSAT-3/COSMIC mission," IEEE Trans. Geosci. Remote Sens., vol. 46, no. 11, Nov. 2008.

[26] C.-T. Lin and R.-Y. Liu, "On orbit performance and constellation deployment lessons learnt of FORMOSAT-3/COSMIC satellite attitude control subsystem," ESA GNC, Tralee, Kerry, Ireland, Jun. 2-5, 2008.

[27] M. D. Cheng et al., FORMOSAT-3/COSMIC radio occultation data verification report-March 2007, Mar. 2007, Taipei, Taiwan: Central Weather Bureau. (in Traditional Chinese), Internal Report.

[28] C. H. Lin, W. B. Wang, M. E. Hagan, C. C. Hsiao, T. J. Immel, M. L. Hsu, J. Y. Liu, L. J. Paxton, T. W. Fang, and C. H. Liu, "Plausible effect of atmospheric tides on the equatorial ionosphere observed by the FORMOSAT-3/COSMIC: Three-dimensional electron density structures," Geophys. Res. Lett., vol. 34, no. 11, p. L11 112, Jun. 2007. DOI: 10.1029/2007GL029265.

[29] C. H. Lin, C. C. Hsiao, J. Y. Liu, and C. H. Liu, "Longitudinal structure of the equatorial ionosphere: Time evolution of the four-peaked EIA structure," J. Geophys. Res., vol. 112, no. A12, p. A12 305, Dec. 2007. DOI: $10.1029 / 2007$ JA012455.

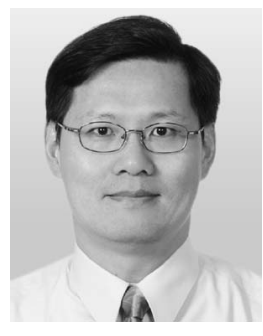

Chen-Joe Fong (S'04-M'08) received the B.S.E.E. and M.S.E.E. degrees in electrophysics and electrooptical engineering from the National Chiao Tung University (NCTU), Hsinchu, Taiwan, in 1983 and 1985 , respectively, where he is currently working toward the Ph.D. degree in the Department of Photonics and Institute of Electro-Optical Engineering.

$\mathrm{He}$ is also currently the FORMOSAT-3 program Systems Engineering Manager of National Space Organization (NSPO), Hsinchu. During the FORMOSAT-3/COSMIC mission operation phase, he is a Spacecraft Lead and responsible for the anomaly resolution team. He has been with NSPO since 1993, where he was a Satellite Integration \& Test (I\&T) Project Manager of ROCSAT-1 program and I\&T division Director. From 1987 to 1993, he was a Microwave Lab Head with the Center for Measurement Standards and a Systems Engineer with the Center for Aviation and Space Technology, Industrial Technology Research Institute, for ROCSAT-1 program. His current research interests include incoherent time-domain pump fiber Raman amplifier, optical soliton, GPS radio occultation, systems engineering, and mission simulation.

Mr. Fong is a member of AIAA, OSA, AASRC, and Phi Tau Phi.

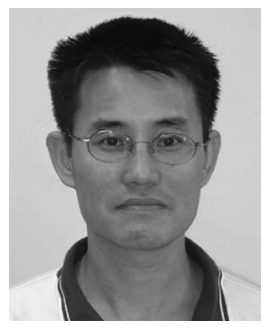

Shan-Kuo (Eddy) Yang received the M.S. degree in engineering science from the National Cheng Kung University, Tainan, Taiwan, in 1987.

Since 1993, he has been with the National Space Organization, Hsinchu, Taiwan, where he was in charge of End-To-End Test between ground segment and space segment and in charge of the communication infrastructure setup and interphase test between SOCC and the remote ground stations during FORMOSAT-3 I\&T phase. He is currently the Deputy Operation Director of FORMOSAT-3 Mission Operation Team. His current research interests include GPS radio occultation for the FORMOSAT-3 follow-on mission, satellite simulator, mission planning and scheduling, and long-term trending development.

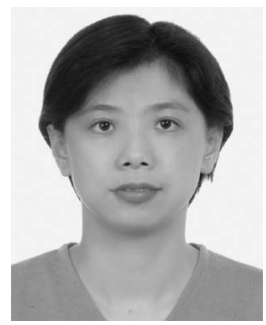

Chung-Huei (Vicky) Chu received the B.S. degree in atmospheric sciences from the National Taiwan University, Taipei, Taiwan and the M.S. degree in meteorology from Penn State University, University Park.

She is currently the FORMOSAT-3/COSMIC Mission Operations Manager of National Space Organization, Hsinchu, Taiwan. She has worked on FORMOSAT series satellite programs since 1994. She spent one year in the development of science data processing, five years in the flight operations and ground operations, and six years in mission analysis and system engineering.

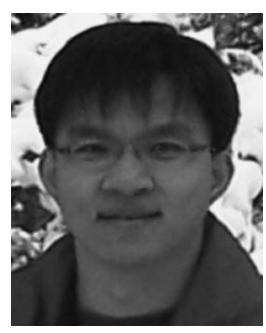

Cheng-Yung Huang received the B.S. degree in atmospheric science, the M.S. degree, and Ph.D. degree in space science from the National Central University, Chungli, Taiwan, in 1995, 1997, and 2005, respectively.

From 2005 to 2007, he was with the National Space Organization, Hsinchu, Taiwan, where he developed radio occultation atmospheric profile retrieval method and analyzed the GPS Occultation Experiment data and provided science information to support FORMOSAT-3 satellites operation. He has been a Post Doctor with the Institute for Scientific Research, Boston College, Chestnut Hill, MA, since November 2007. He is currently working on neutral density in ionosphere. 


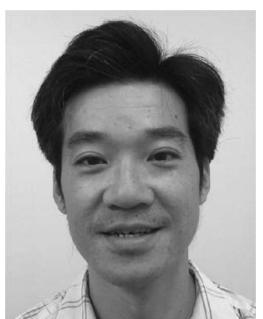

Jia-Jing (James) Yeh received the B.S. and M.S. degrees in physics from the National Cheng Kung University, Tainan, Taiwan, in 1987 and 1989, respectively.

Since 1992, he has been with the National Space Organization (NSPO), Hsinchu, Taiwan, where has been responsible for the electrical power subsystem development of FORMOSAT series satellites. He also served as a responsible Engineer for the validation and testing engineering of subsystem as well as satellite launch countdown activities. Currently, he is developing a satellite power simulator and leading a team to develop power control electronics. He is currently in charge of Satellite Power Department in NSPO.

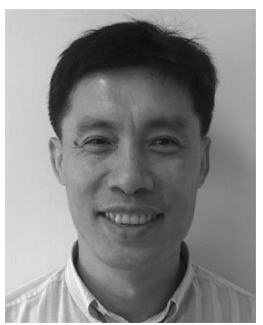

Chen-Tsung (Tom) Lin received the B.S. degree in electrical engineering from the National Taiwan University of Science and Technology, Taipei, Taiwan, in 1988, and the M.S. degree in control system engineering from the National Chiao Tung University, Hsinchu, Taiwan, in 1994.

$\mathrm{He}$ is currently with the National Space Organization, Hsinchu, where he is responsible for FORMOSAT-2 and FORMOSAT-3 Attitude Determination and Control Subsystem. His current research interests include attitude determination, attitude control, engineering development model, hardware in the loop test, and GPS simulation.

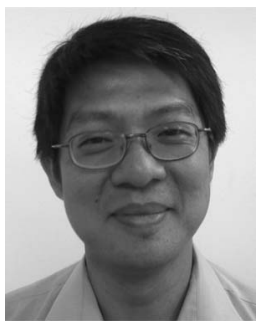

Tien-Chuan Kuo received the B.S., M.S., and Ph.D. degrees in nuclear engineering from the National Tsing Hua University, Hsinchu, Taiwan, in 1988, 1990 , and 1996, respectively.

Since 1996, he has been with the National Space Organization (NSPO), Hsinchu, where he is currently in charge of the propulsion subsystem of the FORMOSAT-serious satellite programs as well as the NSPO interior propulsion development programs. He has 11-year design, analysis, and engineering experience of the spacecraft propulsion system. He has also published 30 journals and conference papers in the areas of satellite propulsion, computational fluid dynamics, Monte Carlo simulations, multiphase flows, phase distribution mechanism, turbulent flow modeling, and particle image velocimetry.

Dr. Kuo is a member of AIAA, NMA, and Phi Tau Phi.

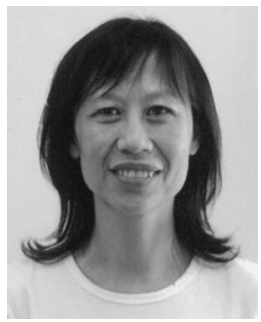

Tie-Yue Liu received the B.S. degree in chemistry from Soochow University, Taipei, Taiwan, and the $\mathrm{Ph} . \mathrm{D}$. degree from the University of South Florida, Tampa.

Since 1993, she has been with the National Space Organization, Hsinchu, Taiwan, working on FORMOSAT series satellite programs. She coordinates domestic science projects and international collaboration. Her current research interests include radio occultation constellation science missions.

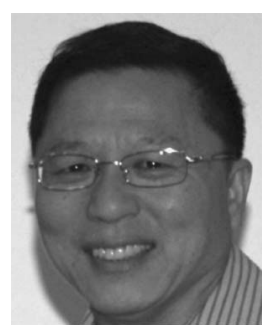

Nick L. Yen received the M.S. degree in mechanical engineering from the Oregon State University, Corvallis, in 1980.

$\mathrm{He}$ is with the National Space Organization, Hsinchu, Taiwan, in 2004 as the Deputy Program Director and soon became the Program Director of FORMOSAT-3/COSMIC Program. He was with the Space Systems/Loral (SS/L), Palo Alto, CA, from 1992 to 2003. He held many key positions in SSL, including SUPERBIRD Senior System Engineer, MBSAT Antenna Subsystem Manager, Control Mechanisms Department Manager, Launch Integration and Launch Operation Department Manager, and Europe* Star Deputy Executive Director. Before that, he was with Ford Aerospace Corporation (former SS/L), Palo Alto, from 1986 to 1992, where he was primarily an Antenna Design Engineer and Antenna Project Manager. Ford Aerospace Corporation was acquired by Loral Corporation and became SS/L in 1992. He was with RCA, East Windsor, NJ, in 1985 as an Antenna Design/Analysis Engineer. He was also with Ford Aerospace Corporation from 1981 to 1984, after the graduate school from Oregon State University, as an Antenna Design/Analysis Engineer. His current research interests include front-to-end process, systems engineering, and FORMOSAT-3 Follow-On constellation mission.

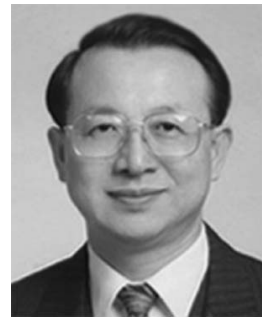

Shao-Shing Chen received the B.E. degree from Chung Cheng Institute of Technology, Tashi, Taiwan, the MBA degree from the National Chengchi University, Taipei, Taiwan, and the Ph.D. degree from the Oklahoma State University, Stillwater.

$\mathrm{He}$ has a 30-year aerospace engineering work experience. He is currently the Deputy Director General with the National Space Organization (NSPO), Hsinchu, Taiwan The FORMOSAT-3/COSMIC program is under his supervision. Prior to NSPO, he was the Deputy Director with the National Precision Instrument Development Center. He was also with Chung-Shan Institute of Science and Technology, Longtan Township, where he served as the Director of the Planning Division, the Section Head of International Cooperation, a QC Engineer, a Reliability Engineer, and QA Planning Officer. He is the author of numerous articles.

Dr. Chen is a member of American Society of Quality Control, Institute of Industrial Engineers, Aeronautical and Astronautical Society of the Republic of China, Chinese Society of Quality Control, Chinese Institute of Industrial Engineers, and Alpha Pi Mu, as well as the adviser of several governmental departments and organizations. He has received a great deal of awards from quality and engineering.

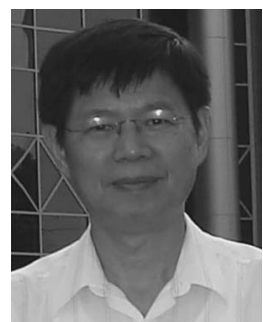

Ying-Hwa Kuo received the B.S. degree in atmospheric sciences from National Taiwan University, Taipei, Taiwan, in 1976, the M.S. degree from South Dakota School of Mines and Technology, Rapid City, in 1979, and the Ph.D. degree from Pennsylvania State University, University Park, in 1983.

$\mathrm{He}$ is currently the Director of the COSMIC Program of the University Corporation for Atmospheric Research (UCAR), Boulder, CO, and the Head of the Mesoscale Prediction Group/MMM Division with the National Center for Atmospheric Research (NCAR), UCAR. He is a recognized leader in the field of mesoscale numerical modeling, meteorological data assimilation, and applications of the GPS radio occultation observation technique. He has served as the NCAR advisor for more than $20 \mathrm{Ph} . D$. students since 1988 . He has authored more than 120 journal papers and numerous conference proceeding articles and reports. His research interest includes mesoscale modeling, explosive marine cyclogenesis, mesoscale convective systems, heavy rainfall prediction, data assimilation, GPS/MET research, and model initialization. 


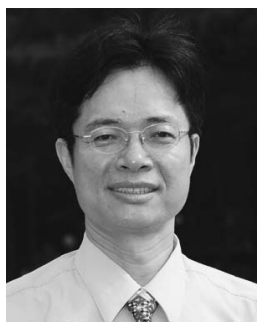

Yuei-An Liou (S'91-M'96-SM'01) received the B.S. degree in electrical engineering from the National Sun Yat-Sen University, Kaohsiung, Taiwan, in 1987, and the M.S.E. degree in electrical engineering, the M.S. degree in atmospheric and space sciences, and the Ph.D. degree in electrical engineering and atmospheric, oceanic, and space sciences from the University of Michigan, Ann Arbor, in 1992, 1994, and 1996, respectively.

From 1989 to 1990, he was a Research Assistant with the Robotics Laboratory, National Taiwan University, Taipei, Taiwan. From 1991 to 1996, he was a Graduate Student Research Assistant with the Radiation Laboratory, University of Michigan, where he developed land-air interaction and microwave emission models for prairie grassland. He was with the faculty at the Center for Space and Remote Sensing Research (CSRSR) in 1996, Institute of Space Sciences in 1997, and Department of Electrical Engineering, all at the National Central University (NCU), Chungli, Taiwan, in 2005, where he is currently a Professor and the Director of CSRSR. He served as a Division Director of the Science Research Division, National Space Organization (NSPO), Hsinchu, Taiwan, in 2005, and continued to serve as an Advisor to NSPO in 2006. From August 2006 to July 2007, he was a Chair Professor and Dean of the College of Electrical Engineering and Computer Science, Ching Yun University, Chungli. His current research activities include GPS meteorology and ionosphere, remote sensing of the atmosphere and land surface, land surface processes modeling, and application of neural networks and fuzzy systems in inversion problems. He is a Principal Investigator on many research projects sponsored by the National Science Council (NSC), Council of Agriculture, NSPO, Civil Aeronautics Administration, Minister of Interior, Water Conservancy Agency of Taiwan, and Office of Naval Research of USA. He has over 70 referral papers and more than 200 international conference papers.

Dr. Liou is a member of the Editorial Advisory Board to GPS Solutions. $\mathrm{He}$ is also a member of the American Geophysical Union, the American Meteorological Society, and the International Association of Hydrological Sciences. He serves as a Guest Editor for the June 2005 Special Issue of "GPS Radio Occultation (RO) Experiments" of GPS Solutions. He also serves as a Leading Guest Editor for the IEEE TGRS special issue "Meteorology, Climate, Ionosphere, Geodesy, and Reflections from the Ocean surfaces: Studies by Radio Occultation Methods." He also serves as an Associated Editor of IEEEJSTARS starting from 2008. He is listed in Who's Who in the World. He was a recipient of Annual Research Awards from NSC in 1998, 1999, and 2000; a recipient of The First Class Research Awards from NSC in 2004, 2005, and 2006; and a recipient of NCU Outstanding Research Awards in 2004 and 2006. He was awarded "Contribution Award to FORMOSAT3 National Space Mission" by NSPO in 2006. He was awarded Honorary Life Member of The Korean Society of Remote Sensing in 2007. He was elected as foreign member of Russian Academy of Engineering Sciences in 2008. He was awarded Outstanding Alumni Award by the University of Michigan Alumni Association in Taiwan in 2008. He is a Referee for Terrestrial, Atmospheric and Oceanic Sciences; IEEE TRANSACTIONS ON GEOSCIENCE AND REMOTE SENSING; Asian Journal of Geoinformatics; International Journal of Remote Sensing; Earth, Planets, and Space; Water Resources Research; Environmental Modelling and Software; Remote Sensing of Environment; J. Geophys. Res.; and Annales Geophysicae.

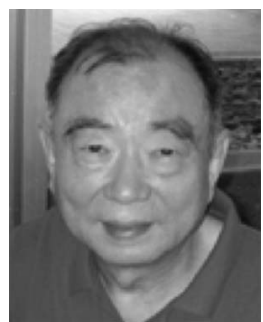

Sien Chi received the B.S.E.E. degree from the National Taiwan University, Taipei, Taiwan, in 1959, the M.S.E.E. degree from the National Chiao Tung University (NCTU), Hsinchu, Taiwan, in 1961, and the Ph.D. degree in electrophysics from the Polytechnic Institute of Brooklyn, Brooklyn, NY, in 1971.

He is currently a Professor of electrooptical engineering with the Department of Photonics and Institute of Electro-Optical Engineering, NCTU. He is also with the Department of Electrical Engineering, Yuan Ze University, Chungli, Taiwan. From 1972 to 1973, he chaired the Department of Electrophysics; from 1973 to 1977, he directed the Institute of Electronics; from 1977 to 1978, he was a Resident Visitor with Bell Lab., Holmdel, NJ; from 1985 to 1988, he was the Principal Advisor with the Hua-Eng Wires and Cables Company, Taiwan; from 1988 to 1990, he directed the Institute of Electro-Optical Engineering; and from 1998 to 2001, he was the NCTU Vice President. He was the symposium Chair of the International Symposium of Optoelectronics in Computers, Communications and Control in 1992, which was coorganized by NCTU and SPIE. Since 1996, he has been the Chair Professor of the Foundation for Advancement of Outstanding Scholarship. His research interests include optical fiber communications, optical solitons, and optical fiber amplifiers.

Dr. Chi is a Fellow of OSA and the Photonics Society of Chinese-Americans. He received the Distinguished Research Award sponsored by the National Science Council from 1993 to 1996. 